\title{
Pyrrole-Embedded Linear and Helical Graphene Nanoribbons
}

Dandan Miao, ${ }^{\dagger}$ Vanessa Di Michele, ${ }^{\neq}$Félix Gagnon, ${ }^{\dagger}$ Cyril Aumaître, ${ }^{\dagger}$ Andrea Lucotti, Mirella Del Zoppo, ${ }^{\neq}$Frédéric Lirette, ${ }^{\dagger}$ Matteo Tommasini, ${ }^{\ddagger}$ and Jean-François Morin ${ }^{\dagger}$ *

† Département de chimie and Centre de Recherche sur les Matériaux Avancés (CERMA), 1045 Ave de la Médecine, Université Laval, Québec, Canada G1V oA6, jean-

francois.morin@chm.ulaval.ca

${ }^{\ddagger}$ Dipartimento di Chimica, Materiali e Ingegneria Chimica « G. Natta », Politecnico di Milano, Piazza Leonardo da Vinci 32, 20133 Milano, Italy 


\section{TABLE OF CONTENT}

General Methods

Apparatus

Experimental section

NMR Spectra

S10

Size-exclusion chromatography

X-ray photoelectron spectroscopy

UV-vis and photoluminescence analysis

Cyclic Voltammetry

S22

Chemical titration of L-PyGNR and H-PyGNR

Raman Spectroscopy

S24

TNT Titration Experiments

S35

Fluorescence Quantum Yields

S36

DFT calculations

S37

References

S80 


\section{GENERAL METHODS}

Chemical reagents were purchased from Sigma-Aldrich Co. Canada, Alfa Aesar Co., TCI America Co. or Oakwood Products Inc. and used as received. Solvents used for organic synthesis were purchased from Fisher Chemical Co., EMD Millipore Co. and CFS Chemical Co. as HPLC grade. These solvents were degassed, dried and purified with a Solvent Purifier System (SPS) (Vacuum Atmosphere Co., Hawthorne, USA). Anhydrous decahydronaphthalene (mixture of cis + trans) was used as received for photochemical reactions and other anhydrous solvents were bought from SigmaAldrich Co. Canada. All anhydrous and air sensitive reactions were performed in ovendried glassware under positive nitrogen stream. Analytical thin-layer chromatographies were performed with silica gel $60 \mathrm{~F} 254,0.25 \mathrm{~mm}$ pre-coated TLC plates (Silicycle, Québec, Canada). Compounds were revealed by a $254 \mathrm{~nm}$ and/or $365 \mathrm{~nm}$ UV wavelength and/or aqueous $\mathrm{K}_{2} \mathrm{CO}_{3}$ and $\mathrm{NaOH}$ solution of potassium permanganate. Flash column chromatographies were performed with 230-400 mesh silica gel R10030B (Silicycle, Québec, Canada). 1,4-dichloro-2,5-diiodobenzene and 2,3dichloro-1,4-diiodobenzene were synthesized according to literature procedures ${ }^{[1]}$ and further purified by recrystallization in isopropanol. 


\section{APPARATUS}

Photochemical reactions were performed in a CCP-ICH2 Luzchem ${ }^{\circledR}$ photochemical reactor equipped with a thermostat and a heating mantle. Photochemical reactions were performed in a $100 \mathrm{~mL}$ quartz round-bottom flask bought from Chemglass ${ }^{\circledR}$. Nuclear magnetic resonance (NMR) spectra were recorded on a Varian Inova AS400 spectrometer (Varian, Palo Alto, USA) at $400 \mathrm{MHz}\left({ }^{1} \mathrm{H}\right)$ and $100 \mathrm{MHz}\left({ }^{13} \mathrm{C}\right)$. Chemical shifts were reported as values ( $\mathrm{ppm})$ relative to residual solvent peak. High resolution mass spectra (HRMS) were recorded with an Agilent 6210 Time-of-Flight (TOF) LCMS apparatus equipped with an APPI ion source (Agilent Technologies, Toronto, Canada). Number-average $(\overline{M n})$ and weight-average $(\overline{M w})$ molecular weights were determined by size-exclusion chromatography (SEC) using a Varian Polymer Laboratories GPC220 equipped with an RI detector and a PL BV400 HT Bridge Viscometer. The column set consists of 2 PL gel Mixed C $(300 \times 7.5 \mathrm{~mm})$ columns and a PL gel Mixed C guard column. The flow rate was fixed at $1 \mathrm{~mL} \mathrm{~min}{ }^{-1}$ using $1,2,4-$ trichlorobenzene (TCB) (with $0.0125 \% \mathrm{BHT} w / \mathrm{v}$ ) as the eluent. The temperature of the system was set to $110^{\circ} \mathrm{C}$. All the samples were prepared at a nominal concentration of $1.0 \mathrm{mg} \mathrm{mL}^{-1}$ in TCB. Dissolution was performed using a Varian Polymer Laboratories PL-SP 260VC sample preparation system. The sample vials were held at $110^{\circ} \mathrm{C}$ with shaking for $1 \mathrm{~h}$ for complete dissolution. The solutions were filtered through a $2 \mathrm{~mm}$ porous stainless steel filter used with a $0.40 \mu \mathrm{m}$ glass filter into a $2 \mathrm{~mL}$ chromatography vial. The calibration method used to generate the reported data was the classical polystyrene method using polystyrene narrow standards Easi-Vials PS-M from Varian Polymer Laboratories which were dissolved in TCB. UV-visible absorption and photoluminescence spectra were recorded on UV-vis HP 8452 and Varian Cary Eclipse Fluorescence Spectrofluorimeter, respectively, using 10-mm path length quartz cells. 
For solid state measurements, the polymer solution $\left(1.0 \mathrm{mg} \mathrm{mL}^{-1}\right.$ in THF) was spin coated on glass plates. Optical bandgaps were calculated from the onset of the absorption band. Cyclic voltammetry (CV) were recorded on a Solartron 1287 potentiostat using platinum wires as the working electrode and counter electrode at a scan rate of $50 \mathrm{mV} \mathrm{s}^{-1}$. The reference electrode was $\mathrm{Ag} / \mathrm{Ag}^{+}\left(0.01 \mathrm{M} \mathrm{AgNO}_{3}\right.$ in acetonitrile) in an anhydrous and argon-saturated solution of $0.1 \mathrm{M}$ tetrabutylammonium hexafluorophosphate $\left(\mathrm{Bu}_{4} \mathrm{NPF}_{6}\right)$ in dry acetonitrile. Under these conditions, the oxidation potential of ferrocene was $0.09 \mathrm{~V}$ versus $\mathrm{Ag} / \mathrm{Ag}^{+}$, whereas the oxidation potential of ferrocene was $0.41 \mathrm{~V}$ versus the saturated calomel electrode (SCE). The HOMO energy levels were determined from the oxidation onsets (where the current starts to differ from the baseline) from the cyclic voltammogram assuming that the $\mathrm{SCE}$ is $-4.71 \mathrm{eV}$ in vacuum, as reported in the literature. ${ }^{[2]}$ The chemical composition of the surface was investigated by X-ray Photoelectron Spectroscopy (XPS), using a PHI 5600-ci spectrometer (Physical Electronics, Eden Prairie, MN, USA). The main XPS chamber was maintained at a base pressure of $<1 \times 10^{-8}$ Torr. A standard aluminium X-ray source $(\mathrm{Al}$ kalpha $=1486.6 \mathrm{eV})$ was used to record survey spectra (1400-0 eV, 10min) with charge neutralization. The detection angle was set at $45^{\circ}$ with respect to the normal of the surface and the analyzed area was $0.125 \mathrm{~mm}^{2}$. 


\section{EXPERIMENTAL SECTION}

\section{1-(2,2"'-dichloro-5'-tetradecyl-[1,1':3',1'-terphenyl]-2'-yl)-1H-pyrrole) (2)}

A round-bottom flask under nitrogen was charged with 1-(4-tetradecyl-2,6-bis(4,4,5,5tetramethyl-1,3,2-dioxaborolan-2-yl)phenyl)-1H-pyrrole (1.00 g, $1.69 \mathrm{mmol}), 1$ bromo-2-chlorobenzene (0.809 g, $4.23 \mathrm{mmol})$ and $2 \mathrm{M} \mathrm{Na}_{2} \mathrm{CO}_{3}$ aqueous solution (8.5 $\mathrm{mL}, 16.9 \mathrm{mmol})$ and flushed three times with a vacuum/nitrogen cycle. Toluene (13.5 $\mathrm{mL})$, EtOH $(2.10 \mathrm{~mL})$ and $\mathrm{H}_{2} \mathrm{O}(1.70 \mathrm{~mL})$ were added and the resulting solution was degassed with a nitrogen stream for 10 mins. $\mathrm{PdCl}_{2}$ (dppf) $(0.138 \mathrm{~g}, 0.169 \mathrm{mmol})$ was added and the reaction flask was flushed three times with a vacuum/nitrogen cycle and heated to $100{ }^{\circ} \mathrm{C}$ for 16 hours. Once cooled to room temperature, $20 \mathrm{~mL}$ of water was added and the aqueous layer was extracted with dichloromethane $(3 \times 50 \mathrm{~mL})$. The organic layer was dried with $\mathrm{Na}_{2} \mathrm{SO}_{4}$ and the solvent was removed under reduced pressure. The resulting residue was purified by silica gel chromatography $(25 \%$ $\mathrm{CH}_{2} \mathrm{Cl}_{2}$ /hexanes) to obtain compound 2 as a light yellow solid $(0.853 \mathrm{~g}, 90 \%) .{ }^{1} \mathrm{H} \mathrm{NMR}$ (400 $\left.\mathrm{MHz} \mathrm{CDCl}_{3}\right): \delta 7.28(\mathrm{~m}, 10 \mathrm{H}), 6.37(\mathrm{~s}, 2 \mathrm{H}), 5.79(\mathrm{~s}, 2 \mathrm{H}), 2.75(\mathrm{~m}, 2 \mathrm{H}), 1.74(\mathrm{~m}$, 2H), $1.29(\mathrm{~m}, 22 \mathrm{H}), 0.91(\mathrm{t}, J=6.8 \mathrm{~Hz}, 3 \mathrm{H}) .{ }^{13} \mathrm{C} \mathrm{NMR}\left(100 \mathrm{MHz}, \mathrm{CDCl}_{3}\right): \delta$ 141.91, $141.56,138.22,137.88,137.14,136.98,135.66,133.96,133.76,133.60,133.27$, $131.17,130.88,130.76,130.63,129.36,128.80,126.29,123.13,122.49,108.20$ $107.61,35.56,32.08,31.35,29.85,29.83,29.81,29.74,29.61,29.52,29.36,22.85$, 14.29. HRMS (APPI+): calculated for $\mathrm{C}_{36} \mathrm{H}_{43} \mathrm{Cl}_{2} \mathrm{~N}(\mathrm{M}+\mathrm{H})^{+}$559.28321, found 559.28796 . 


\section{8-tetradecylbenzo[7,8] indolizino[6,5,4,3-def]phenanthridine (3)}

A quartz flask was oven-dried and flushed three times with a vacuum/nitrogen cycle. Compound 1 (56.1 mg, $0.100 \mathrm{mmol})$ and anhydrous decahydronaphthalene $(100 \mathrm{~mL})$ were added to the flask and the solution was degassed with a continuous flow of argon for 10 minutes. The solution was then irradiated under $254 \mathrm{~nm}$ at $100{ }^{\circ} \mathrm{C}$ for 2 hours under a continuous flow of argon. After cooling down to room temperature, the solvent was removed by vacuum distillation and the resulting residue was purified by silica gel chromatography (100\% hexanes) to obtain compound $\mathbf{3}$ as a dark yellow solid (46.9 mg, 96\%). ${ }^{1} \mathrm{H}$ NMR (400 MHz, $\left.\mathrm{CDCl}_{3}\right): \delta 8.34(\mathrm{~d}, J=4.0 \mathrm{~Hz}, 2 \mathrm{H}), 8.12(\mathrm{~m}, 4 \mathrm{H}), 7.53$ (t, $J=7.4 \mathrm{~Hz}, 2 \mathrm{H}), 7.45(\mathrm{t}, J=7.7 \mathrm{~Hz}, 2 \mathrm{H}), 7.29(\mathrm{~s}, 2 \mathrm{H}), 2.92(\mathrm{t}, J=7.8 \mathrm{~Hz}, 2 \mathrm{H}), 1.81$ (m, 2H), $1.25(\mathrm{~m}, 22 \mathrm{H}), 0.87(\mathrm{t}, J=7.1 \mathrm{~Hz}, 3 \mathrm{H}) .{ }^{13} \mathrm{C} \mathrm{NMR}\left(100 \mathrm{MHz}, \mathrm{CDCl}_{3}\right): \delta 138.25$, $129.38,128.48,126.65,126.09,125.52,125.45,123.17,123.04,122.82,120.54$, $103.53,36.86,32.31,32.08,29.86,29.81,29.79,29.74,29.55,29.52,22.85,14.28$. HRMS (APPI+): calculated for $\mathrm{C}_{36} \mathrm{H}_{41} \mathrm{~N}(\mathrm{M}+\mathrm{H})^{+} 487.32390$, found 487.33225 .

\section{Polymerization Procedure for the Precursors P1, P2}

1-(4-tetradecyl-2,6-bis(4,4,5,5-tetramethyl-1,3,2-dioxaborolan-2-yl)phenyl)-1H-

pyrrole was polymerized with 1,4-dichloro-2,5-diiodobenzene and 2,3-dichloro-1,4diiodobenzene by a palladium-catalyzed Suzuki-Miyaura polymerization to afford the precursors P1 and P2, respectively. A flask under nitrogen was charged with 1-(4tetradecyl-2,6-bis(4,4,5,5-tetramethyl-1,3,2-dioxaborolan-2-yl)phenyl)-1H-pyrrole (1 equiv.), 1,4-dichloro-2,5-diiodobenzene or 2,3-dichloro-1,4-diiodobenzene (1 equiv.), $\mathrm{LiOH} \cdot \mathrm{H}_{2} \mathrm{O}$ (8 equiv.), THF $(0.1 \mathrm{M})$ and $\mathrm{H}_{2} \mathrm{O}(0.8 \mathrm{M})$. The flask was flushed three times with a vacuum/nitrogen cycle and degassed with a continuous flow of nitrogen for 10 
minutes. $\operatorname{Pd}_{2}(\mathrm{dba})_{3}(0.01$ equiv. $)$ and $\mathrm{SPhos}(0.08$ equiv. $)$ were added and the reaction flask was flushed three times using a vacuum/nitrogen cycle and the reaction mixture was heated at $60{ }^{\circ} \mathrm{C}$ for 12 hours. Once cooled to room temperature, the reaction mixture was precipitated in cold methanol under vigorous stirring and filtered through a $0.45 \mu \mathrm{m}$ nylon filter. The residue was purified by Soxhlet extraction in acetone for 24 hours and recovered with hexanes through the extraction thimble. The solvent was removed under reduced pressure in the dark and the solid was dissolved in a minimum amount of hexanes, precipitated in methanol, filtered through a $0.45 \mu$ m nylon filter and thoroughly dried under vacuum.

\section{Polymer P1}

1-(4-tetradecyl-2,6-bis(4,4,5,5-tetramethyl-1,3,2-dioxaborolan-2-yl)phenyl)-1Hpyrrole $(0.250 \mathrm{~g}, 0.423 \mathrm{mmol})$ was polymerized with 1,4-dichloro-2,5-diiodobenzene $(0.169 \mathrm{~g}, 0.423 \mathrm{mmol})$ according to the procedure described above. Polymer P1 $(\overline{\mathrm{Mn}}=$ $\left.16.6 \mathrm{~kg} \mathrm{~mol}^{-1}, \overline{M \mathrm{w}}=29.4 \mathrm{~kg} \mathrm{~mol}^{-1}, \mathrm{PDI}=1.8\right)$ was obtained as a yellow powder $(0.175$ g, 86\%).

\section{Polymer P2}

1-(4-tetradecyl-2,6-bis(4,4,5,5-tetramethyl-1,3,2-dioxaborolan-2-yl)phenyl)-1 $H$ -

pyrrole $(0.250 \mathrm{~g}, 0.423 \mathrm{mmol})$ and 2,3-dichloro-1,4-diiodobenzene $(0.169 \mathrm{~g}, 0.423$ mmol) was copolymerized according to the procedure described above. Polymer P2 $\left(\overline{M \mathrm{n}}=15.8 \mathrm{~kg} \mathrm{~mol}^{-1}, \overline{M \mathrm{w}}=23.3 \mathrm{~kg} \mathrm{~mol}^{-1}, \mathrm{PDI}=1.5\right)$ was obtained as a light yellow powder $(0.179 \mathrm{~g}, 88 \%)$.

Photochemical Procedure for the Synthesis of L-PyGNR and H-PyGNR 
Precursor (P1, P2) was dissolved in anhydrous decahydronaphthalene $(0.002 \mathrm{M})$ in an oven-dried quartz flask under argon. The solution was degassed with a continuous flow of argon for 10 minutes. The solution was heated to $100{ }^{\circ} \mathrm{C}$ and irradiated with $16 \times 7.2$ W low pressure mercury lamps at $\lambda=254 \mathrm{~nm}$ for 72 hours while maintaining a continuous flow of argon. Once cooled down to room temperature, the solvent was removed by vacuum distillation and the solid was dissolved in a minimum amount of THF, precipitated in cold methanol and filtered through a $0.45 \mu$ m nylon filter. The residue was purified by Soxhlet extraction in hexanes for 24 hours and recovered with THF. Once concentrated to a minimum amount of solvent, the polymer was precipitated in methanol, filtered and thoroughly dried under vacuum.

\section{L-PyGNR}

P1 (0.096 g) was subjected to the procedure described above to obtain L-PyGNR $(\overline{M n}$

$\left.=18.5 \mathrm{~kg} \mathrm{~mol}^{-1}, \overline{M \mathrm{w}}=30.7 \mathrm{~kg} \mathrm{~mol}^{-1}, \mathrm{PDI}=1.7\right)$ as a dark brown solid $(0.075 \mathrm{~g}, 92 \%)$.

\section{H-PyGNR}

P2 (0.096 g) was subjected to the procedure described above to obtain H-PyGNR $(\overline{M n}$ $\left.=12.8 \mathrm{~kg} \mathrm{~mol}^{-1}, \overline{M \mathrm{w}}=20.4 \mathrm{~kg} \mathrm{~mol}^{-1}, \mathrm{PDI}=1.6\right)$ as a dark orange solid $(0.077 \mathrm{~g}, 94 \%)$. 


\section{NMR SPECTRA}

\section{Compound 2}

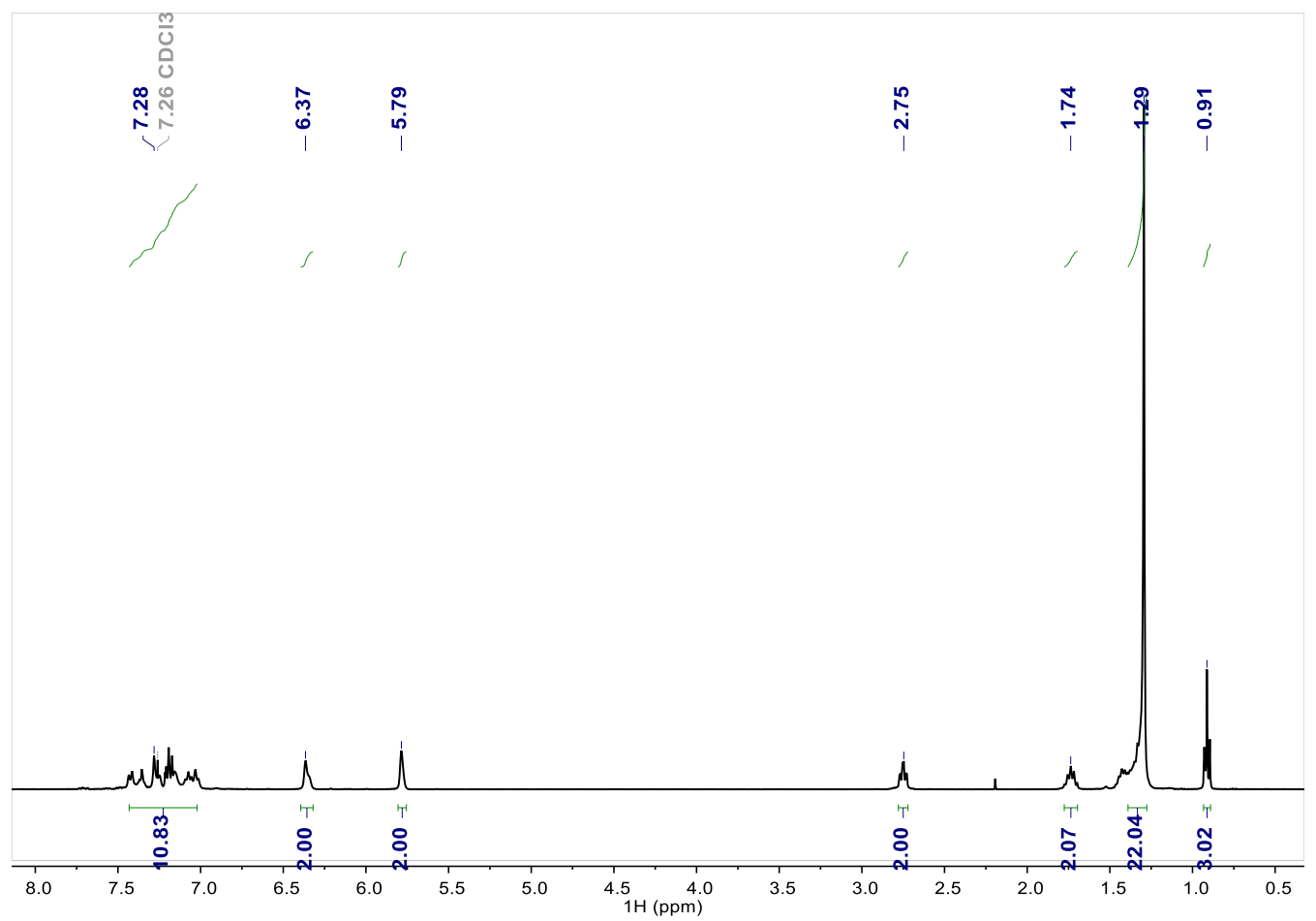

Figure $\mathrm{S} 1:{ }^{1} \mathrm{H}$ NMR spectrum of compound 2 in $\mathrm{CDCl}_{3}$.
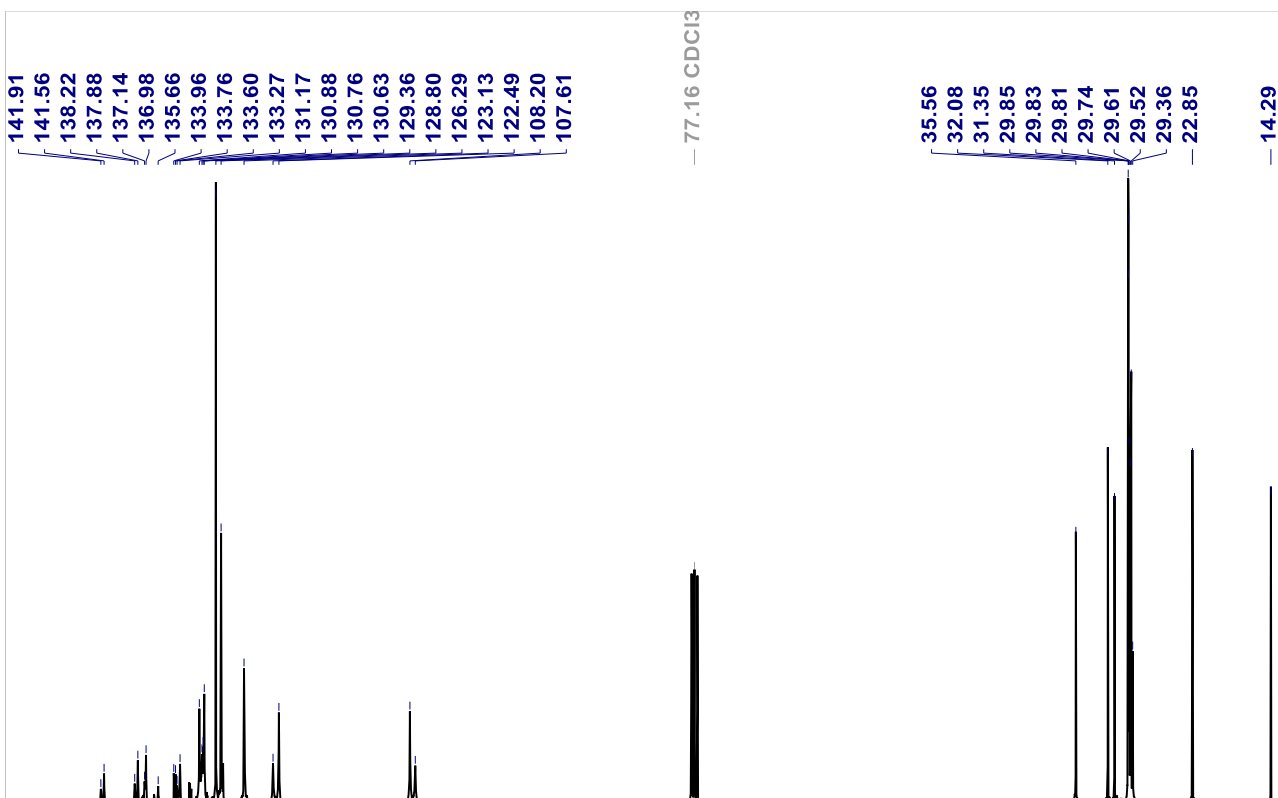

$\begin{array}{lllllllllllllllllllllllllllll}150 & 145 & 140 & 135 & 130 & 125 & 120 & 115 & 110 & 105 & 100 & 95 & 90 & 85 & 80 & 75 & 70 & 65 & 60 & 55 & 50 & 45 & 40 & 35 & 30 & 25 & 20 & 15 & 10\end{array}$

Figure S2: ${ }^{13} \mathrm{C}$ NMR spectrum of compound 2 in $\mathrm{CDCl}_{3}$. 


\section{Compound 3}

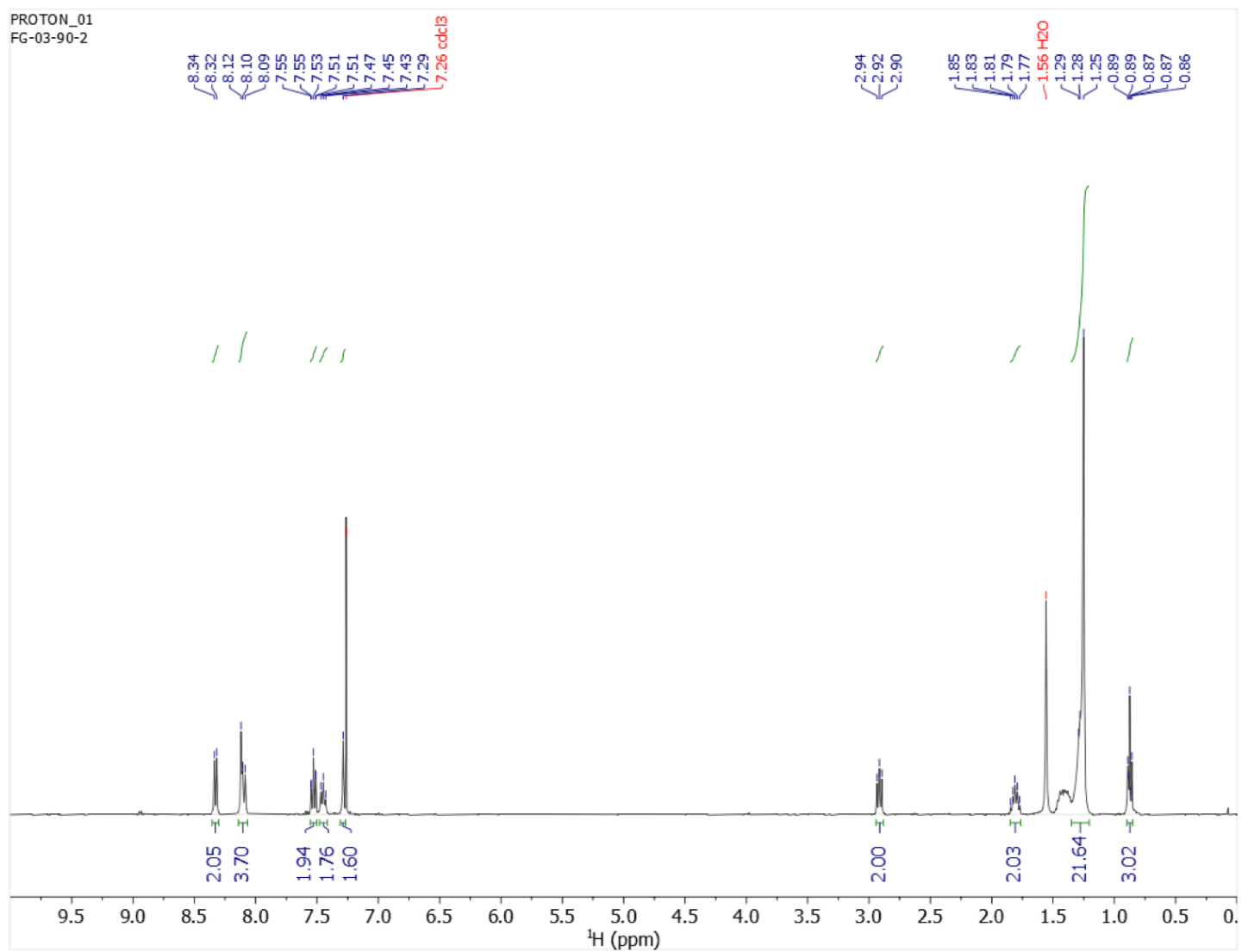

Figure S3: ${ }^{1} \mathrm{H}$ NMR spectrum of compound 3 in $\mathrm{CDCl}_{3}$.

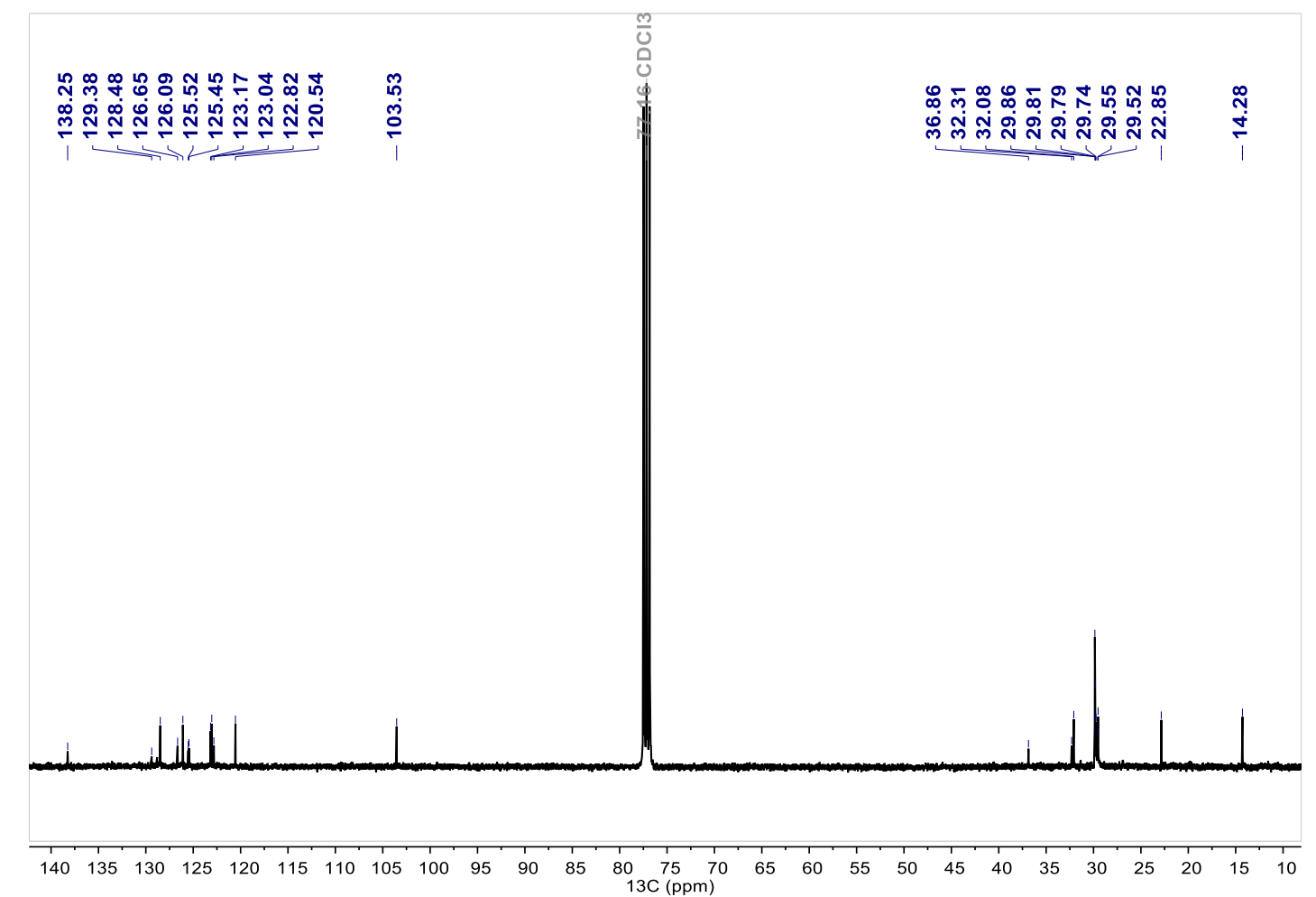


Figure S4: ${ }^{13} \mathrm{C}$ NMR spectrum of compound 3 in $\mathrm{CDCl}_{3}$.

\section{Polymer P1 and L-PyGNR}
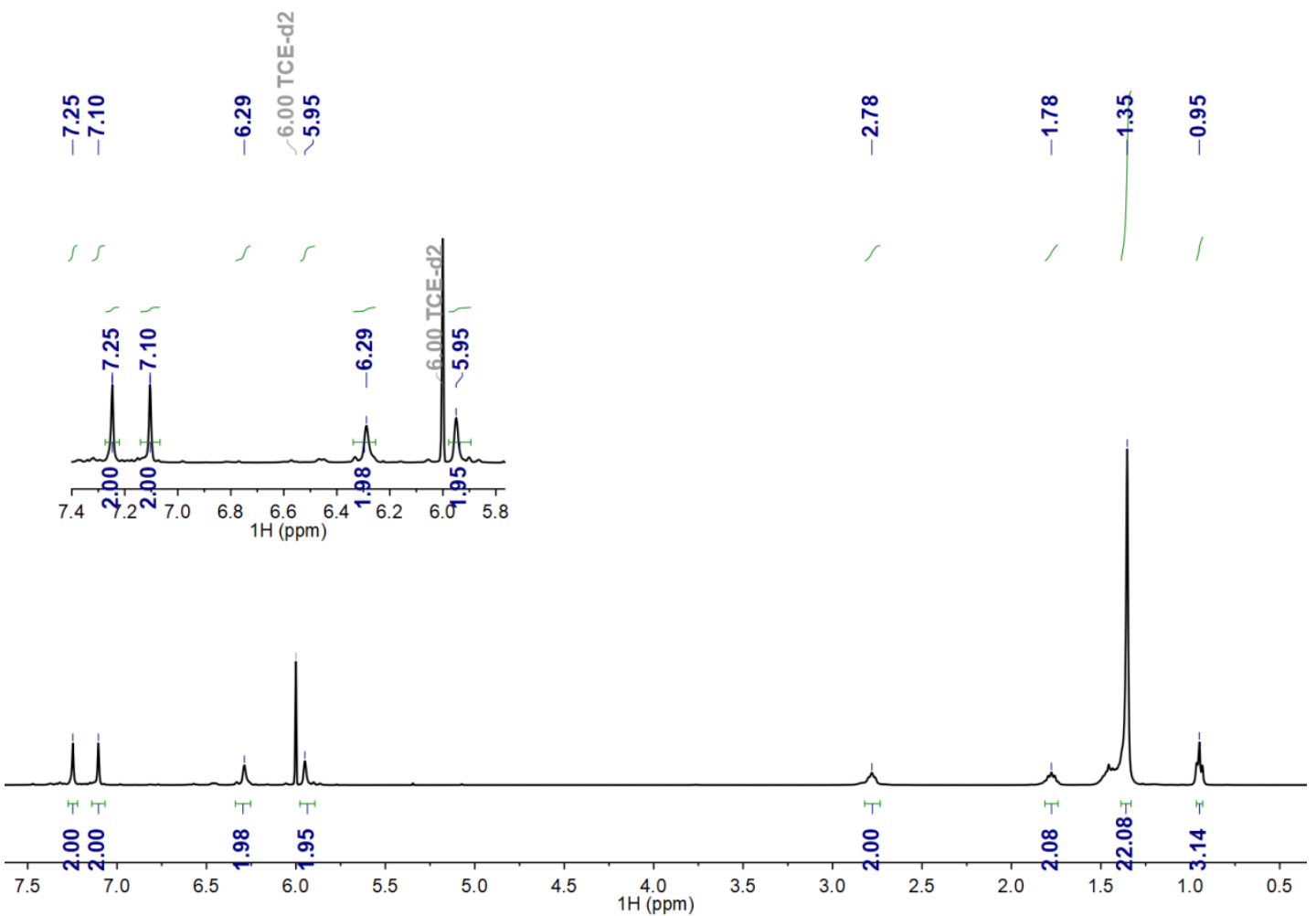

Figure S5: ${ }^{1} \mathrm{H}$ NMR spectrum of $\mathbf{P 1}$ in TCE- $d_{2}$ at $383 \mathrm{~K}$.

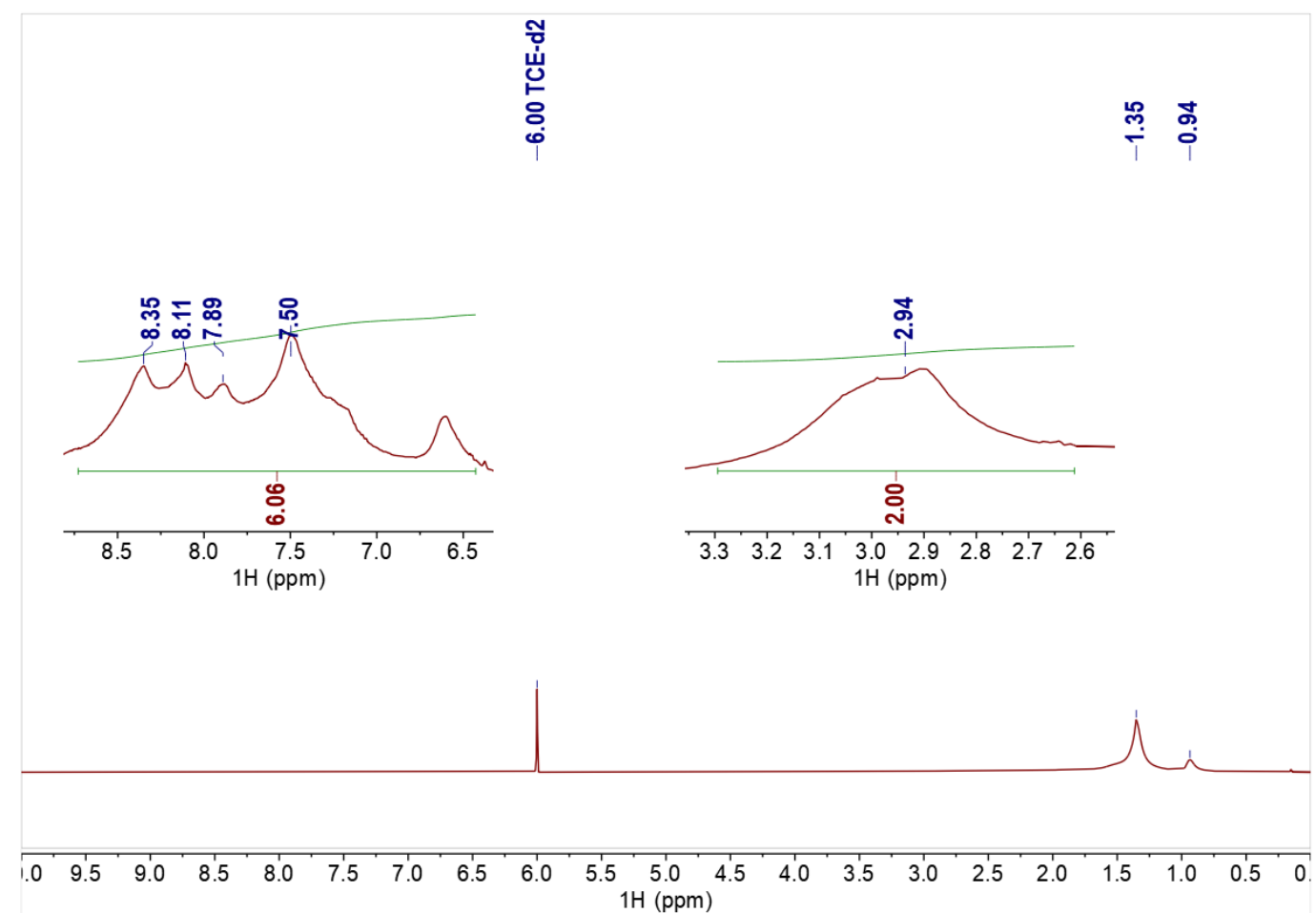


Figure S6: ${ }^{1} \mathrm{H}$ NMR spectrum of L-PyGNR in TCE- $d_{2}$ at $383 \mathrm{~K}$.

\section{Polymer P2 and H-PyGNR}

I
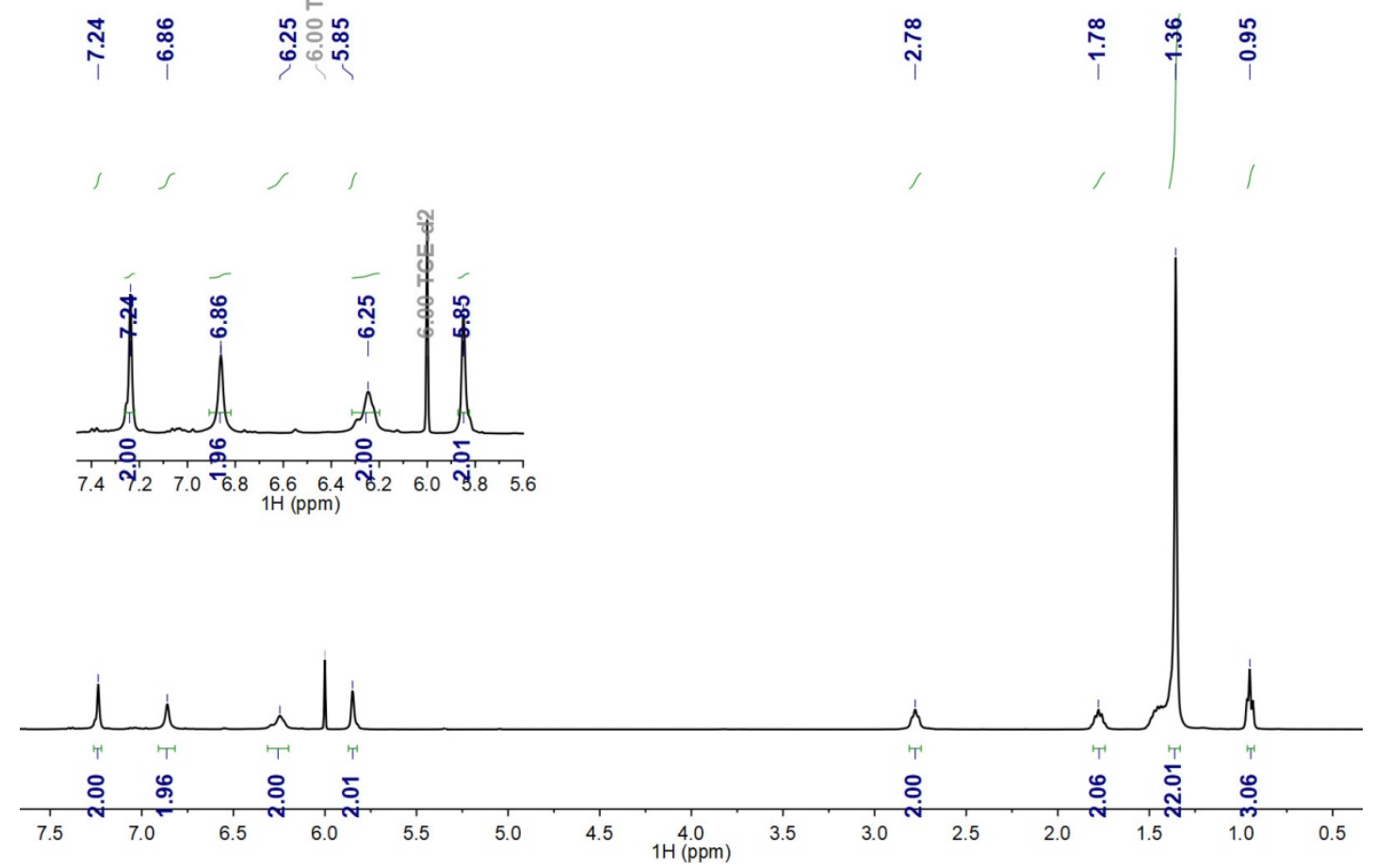

Figure S7: ${ }^{1} \mathrm{H}$ NMR spectrum of $\mathbf{P} 2$ in $\mathrm{TCE}-d_{2}$ at $383 \mathrm{~K}$. 


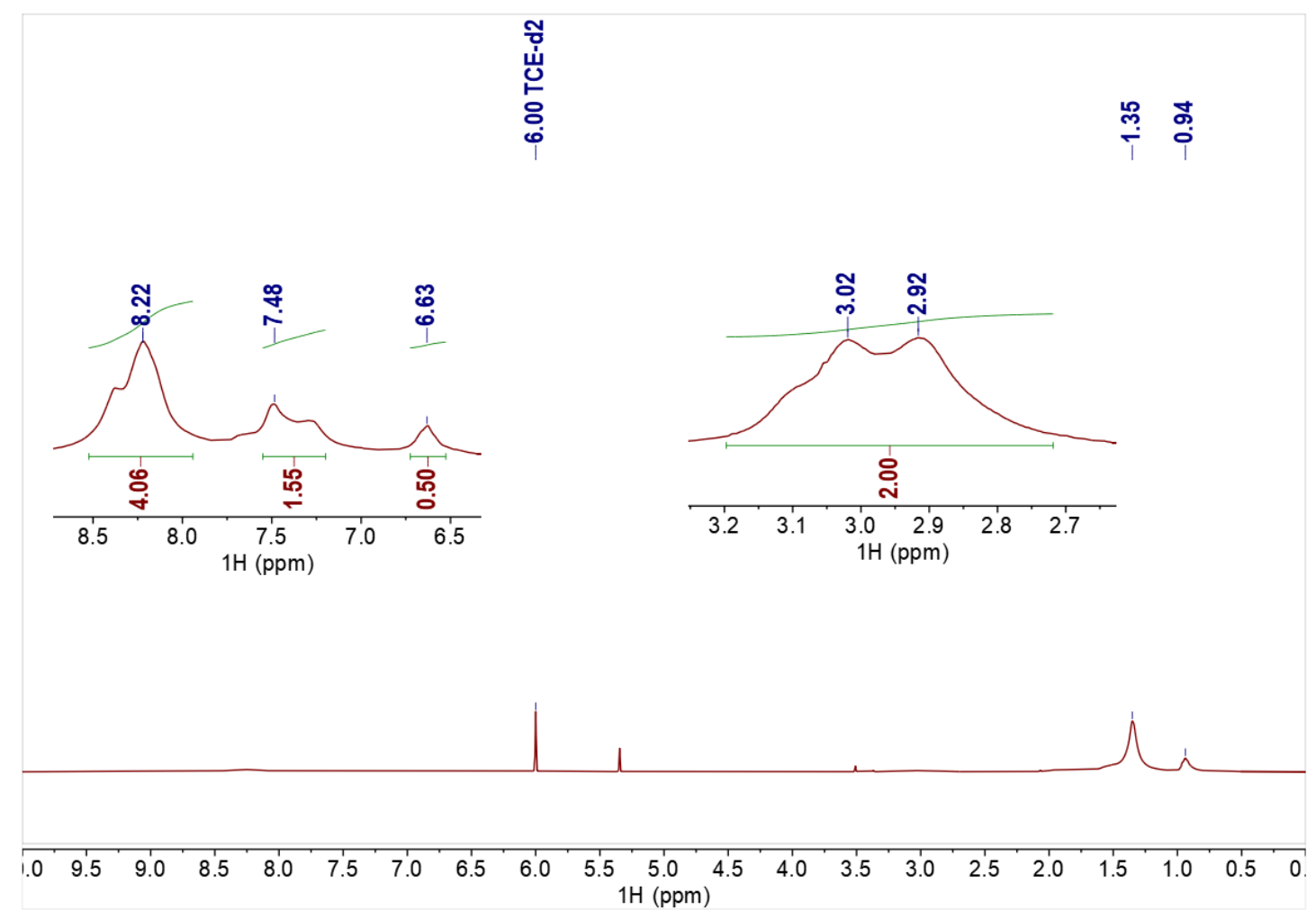

Figure S8: ${ }^{1} \mathrm{H}$ NMR spectrum of H-PyGNR in TCE- $d_{2}$ at $383 \mathrm{~K}$.

\section{SIZE-EXCLUSION CHROMATOGRAPHY}

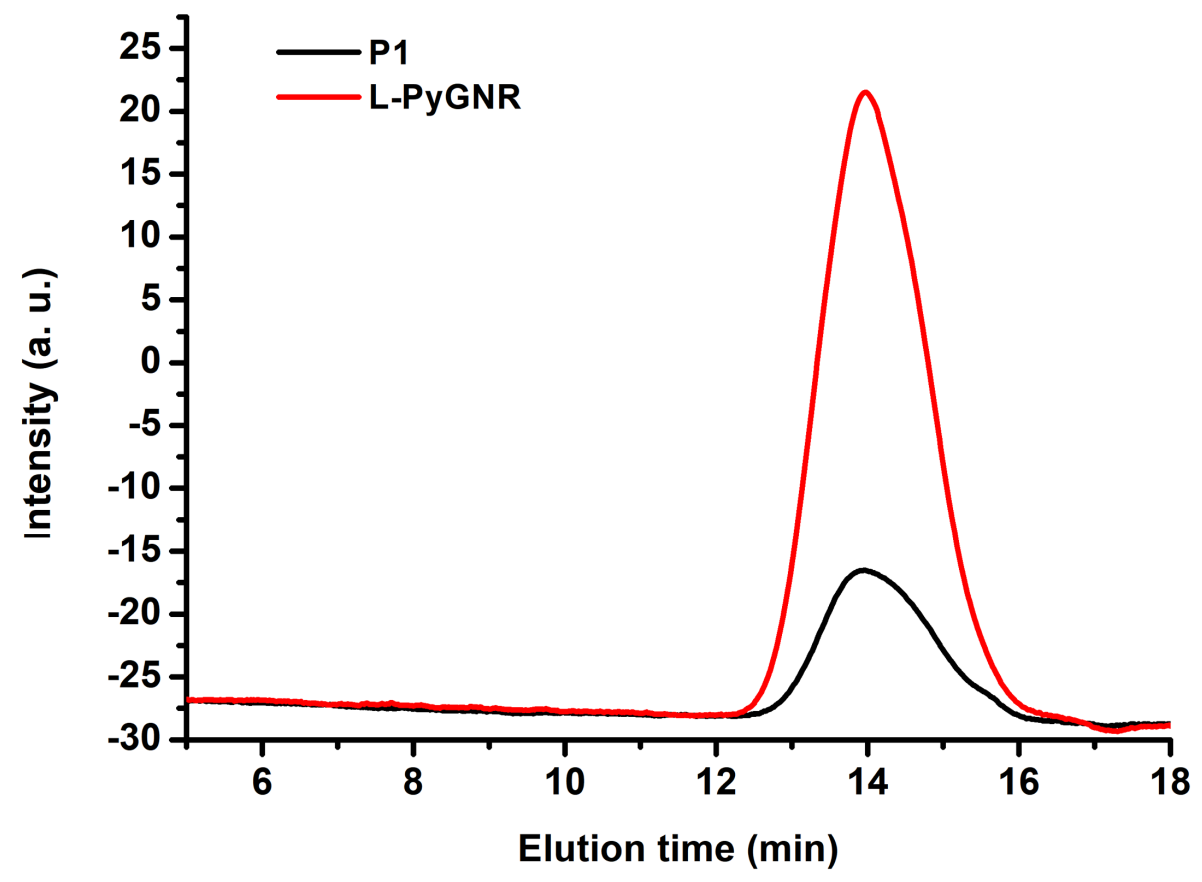


Figure S9: Size exclusion chromatography traces for $\mathbf{P 1}\left(\overline{M \mathrm{n}}: 16.6 \mathrm{~kg} \mathrm{~mol}^{-1}, \overline{M \mathrm{w}}: 29.4\right.$

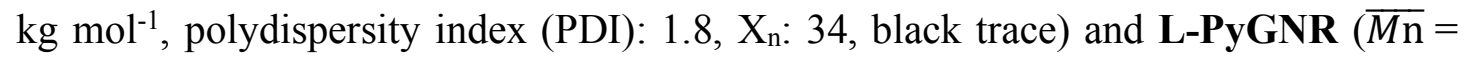
$18.5 \mathrm{~kg} \mathrm{~mol}^{-1}, \overline{M \mathrm{w}}=30.7 \mathrm{~kg} \mathrm{~mol}^{-1}$, polydispersity index (PDI): 1.7 , red trace).

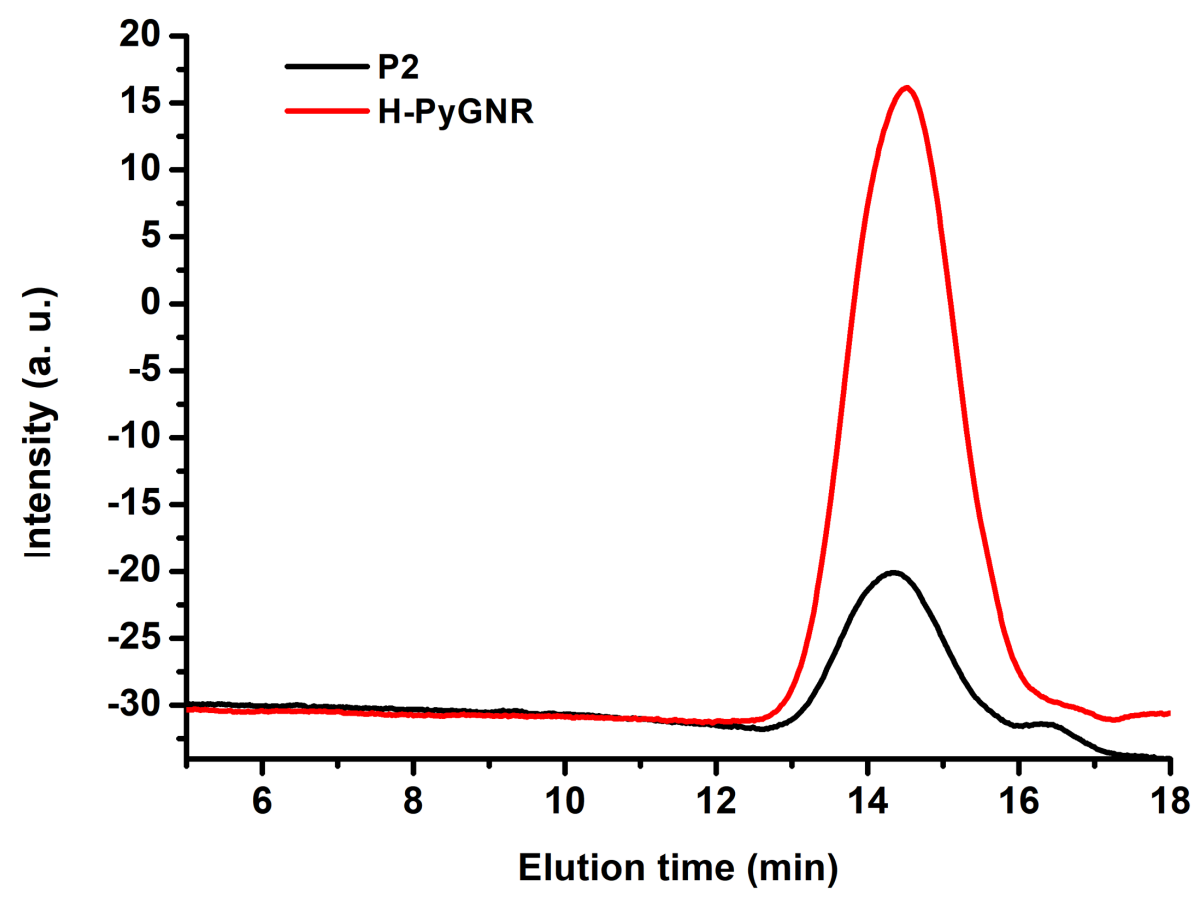


Figure S10: Size exclusion chromatography traces for $\mathbf{P 2}\left(\overline{M \mathrm{n}}: 15.8 \mathrm{~kg} \mathrm{~mol}^{-1}, \overline{M \mathrm{w}}\right.$ : $23.3 \mathrm{~kg} \mathrm{~mol}^{-1}$, polydispersity index (PDI): $1.5, \mathrm{X}_{\mathrm{n}}: 32$, black trace) and H-PyGNR $(\overline{M \mathrm{n}}$ $=12.8 \mathrm{~kg} \mathrm{~mol}^{-1}, \overline{M \mathrm{w}}=20.4 \mathrm{~kg} \mathrm{~mol}^{-1}$, polydispersity index (PDI): 1.6, $\mathrm{X}_{\mathrm{n}}: 31$, red trace).

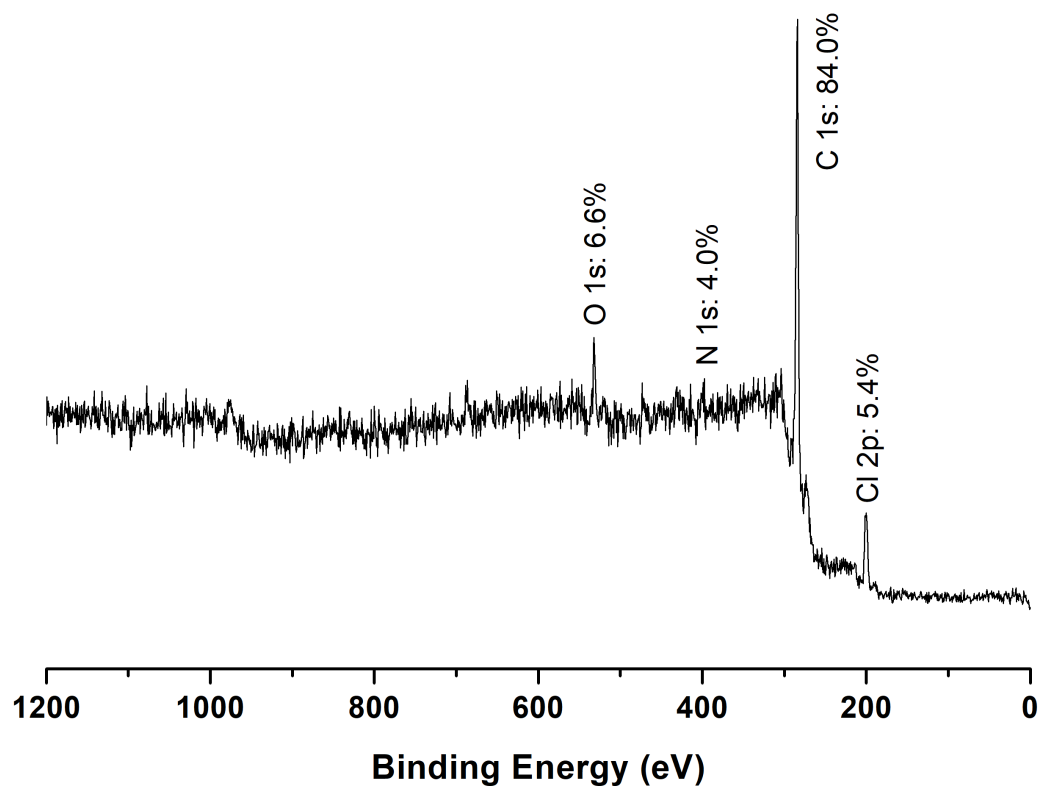


Figure S11: XPS spectrum of P1. The peak located at $200 \mathrm{eV}$ testifies the presence of chlorine atoms in P1. The presence of oxygen is due to the sample holder made of a silicon-based polymer.

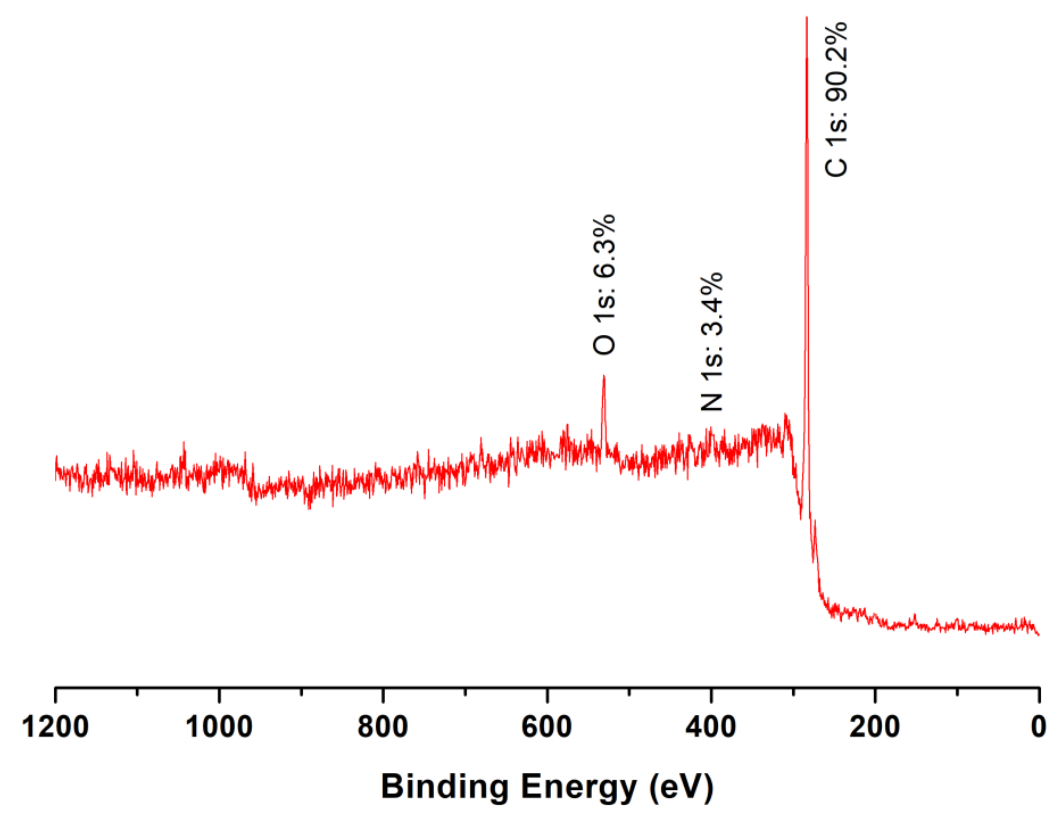

Figure S12: XPS spectrum of L-PyGNR. The complete disappearance of the signal at $200 \mathrm{eV}$ confirms that L-PyGNR is free of chlorine atoms and that the photochemical $\mathrm{CDHC}$ reaction went to completion. The presence of oxygen is due to the sample holder made of a silicon-based polymer. 


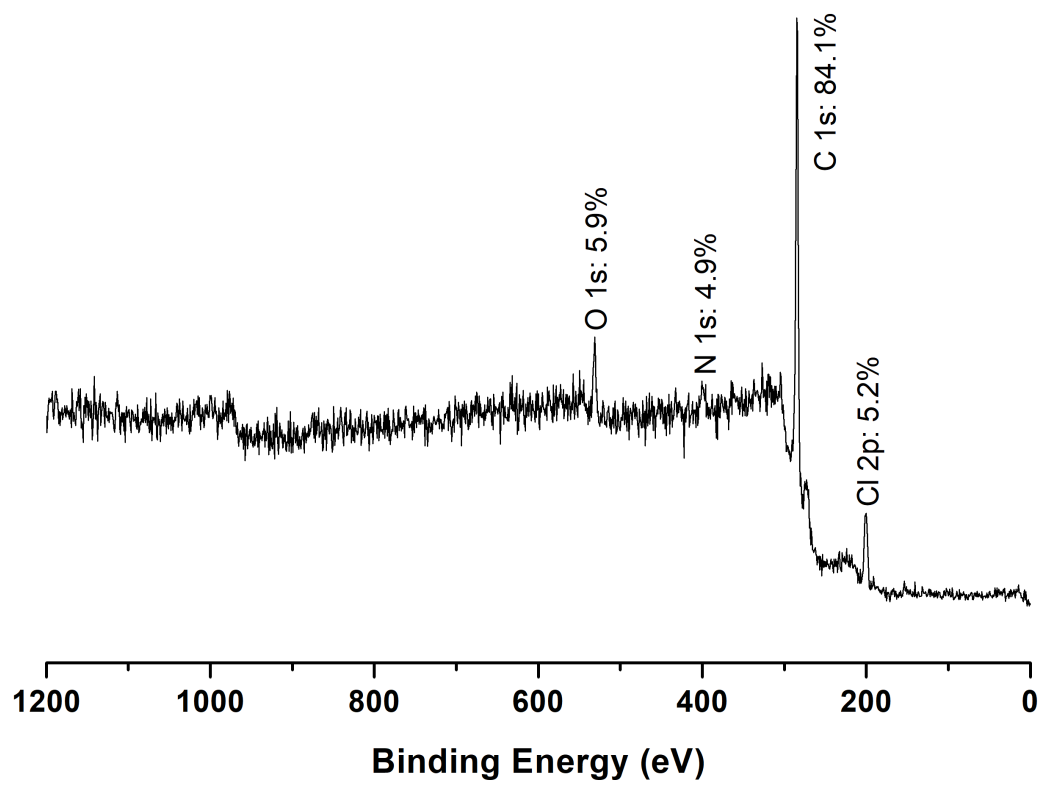

Figure S13: XPS spectrum of P2. The peak located at $200 \mathrm{eV}$ testifies the presence of chlorine atoms in $\mathbf{P 2}$. The presence of oxygen is due to the sample holder made of a silicon-based polymer. 


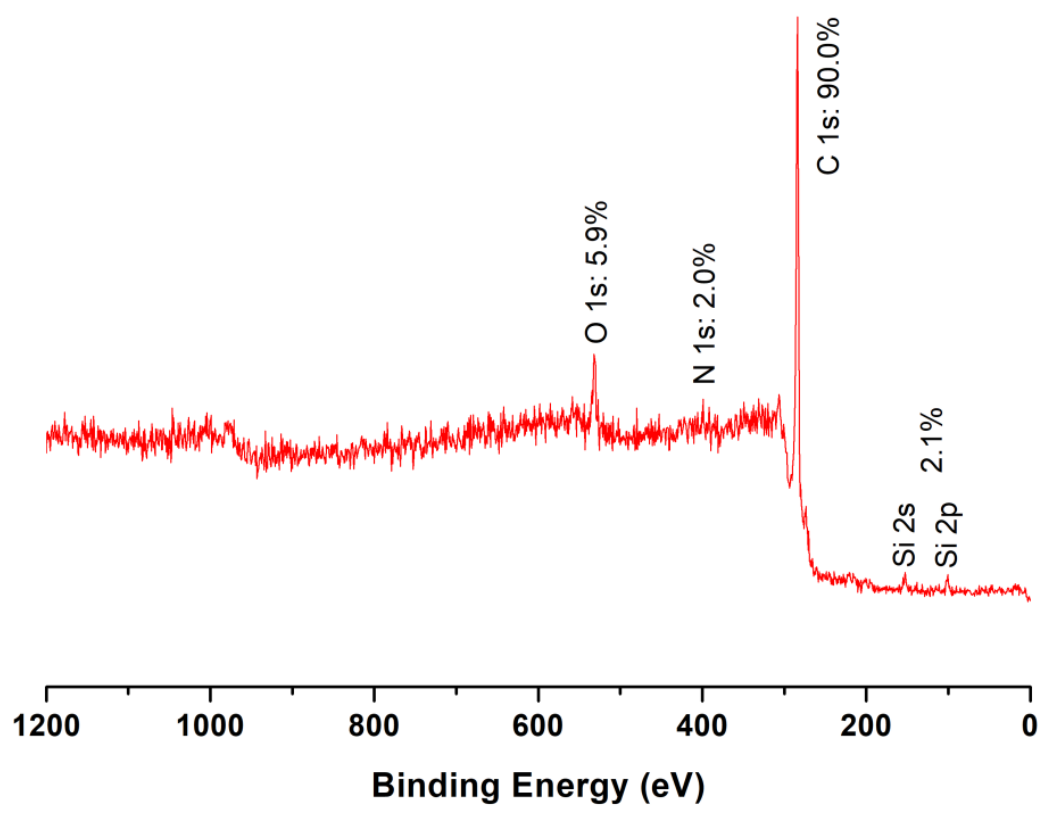

Figure S14: XPS spectrum of H-PyGNR. The complete disappearance of the signal at $200 \mathrm{eV}$ confirms that H-PyGNR is free of chlorine atoms and that the photochemical CDHC reaction went to completion. The presence of silicon and oxygen is due to the sample holder made of a silicon-based polymer. 


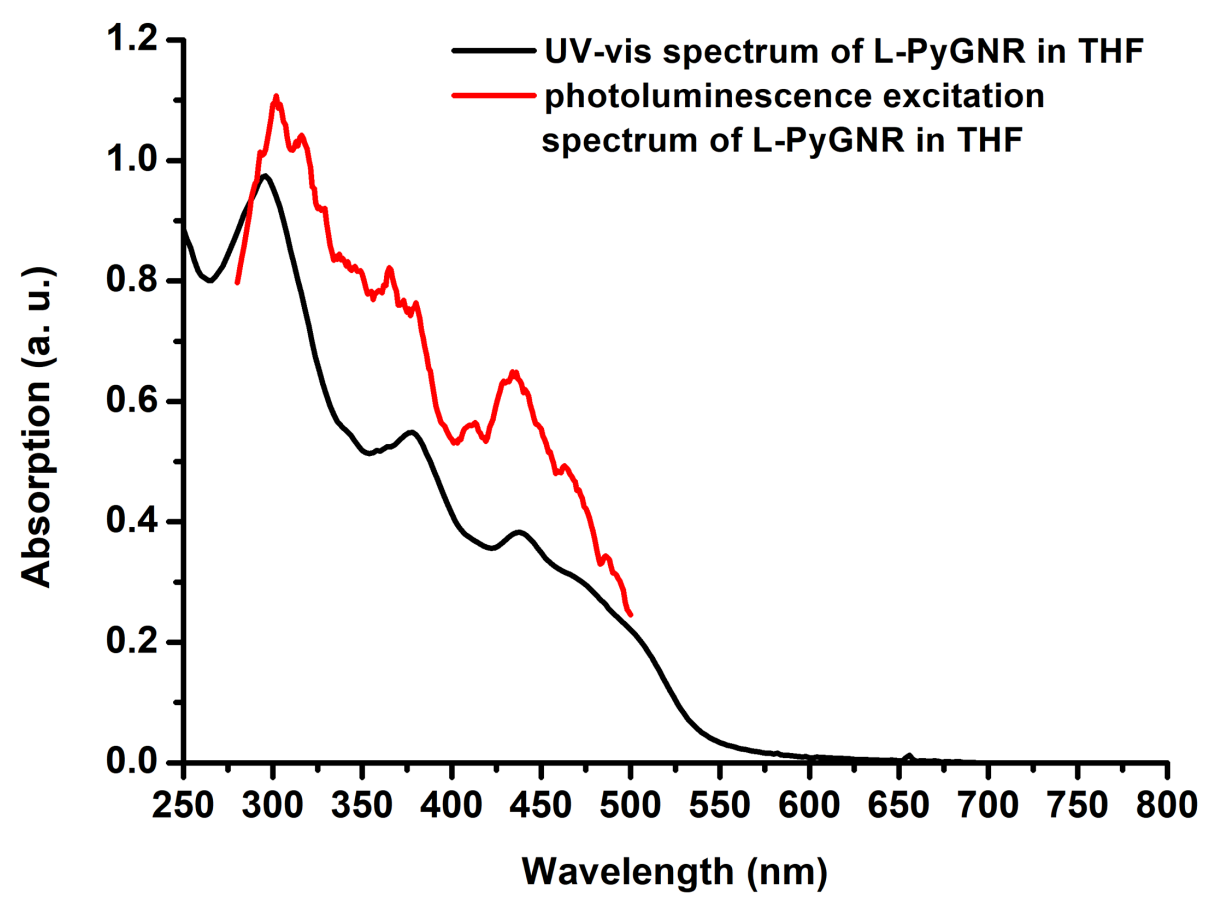

Figure S15: UV-vis absorption (black) and photoluminescence excitation (red, monitored at $\lambda_{\mathrm{em}}=540 \mathrm{~nm}$ ) spectra of L-PyGNR in THF solution. The intensity scale of the excitation spectrum is arbitrary. 


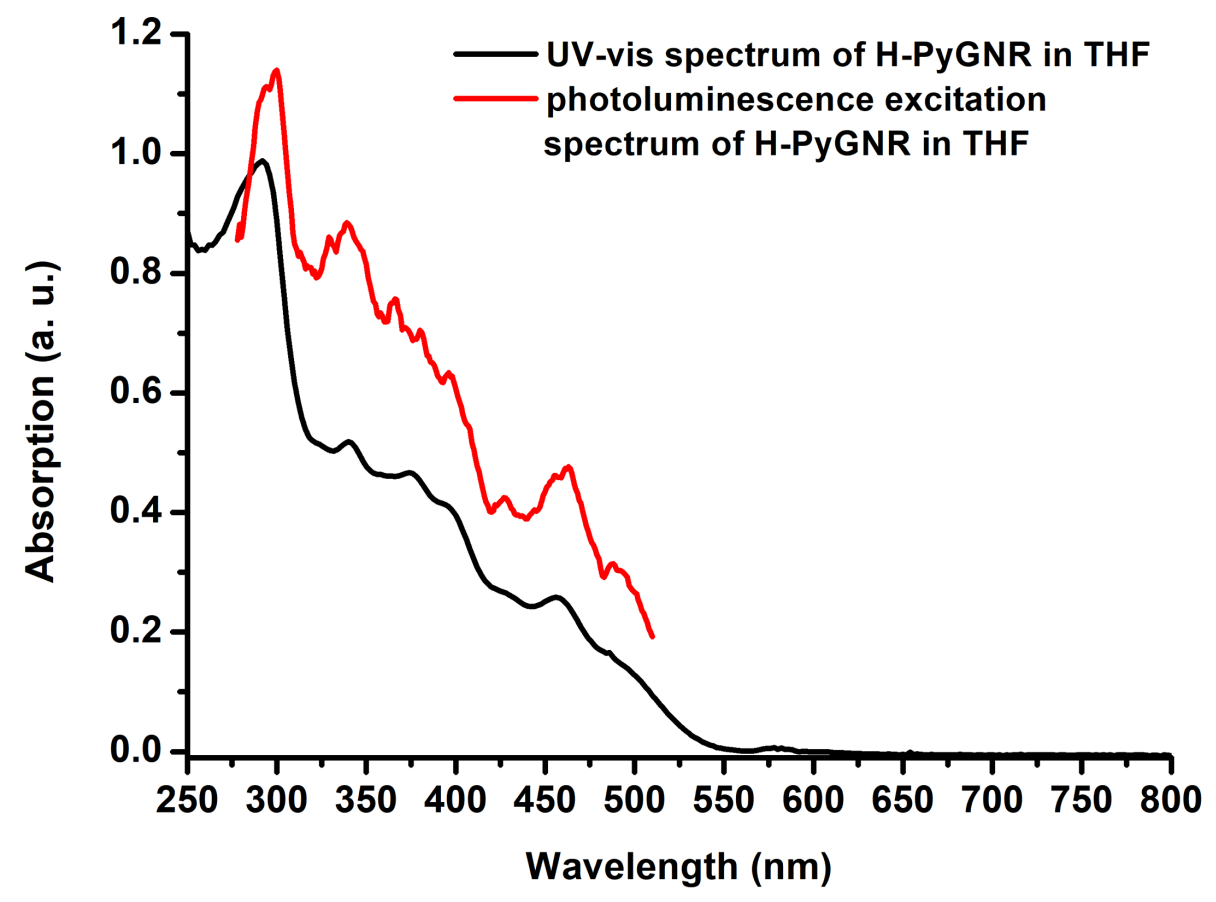

Figure S16: UV-vis absorption (black) and photoluminescence excitation (red, monitored at $\lambda_{\mathrm{em}}=540 \mathrm{~nm}$ ) spectra of H-PyGNR in THF solution. The intensity scale of the excitation spectrum is arbitrary. 


\section{CYCLIC VOLTAMMETRY}

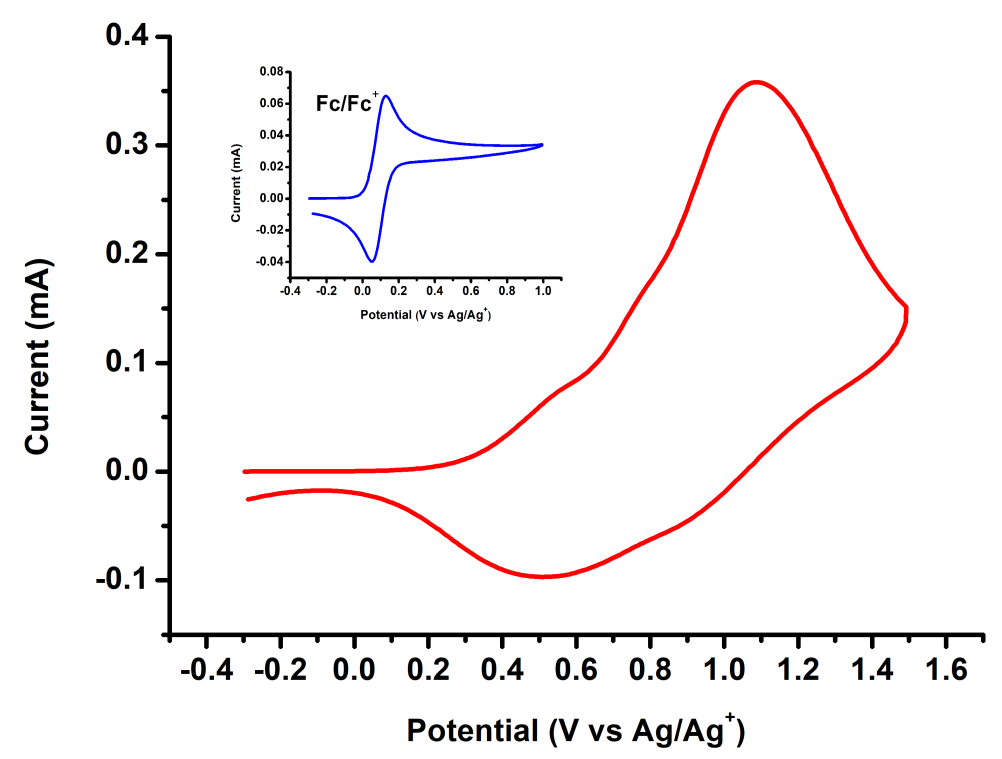

Figure S17: Film Cyclic Voltammetry of L-PyGNR in acetonitrile solution with 0.1 $\mathrm{M} \mathrm{Bu}_{4} \mathrm{NPF}_{6}$ as the supporting electrolyte with a scan rate of $50 \mathrm{mV} \mathrm{s}^{-1}$.

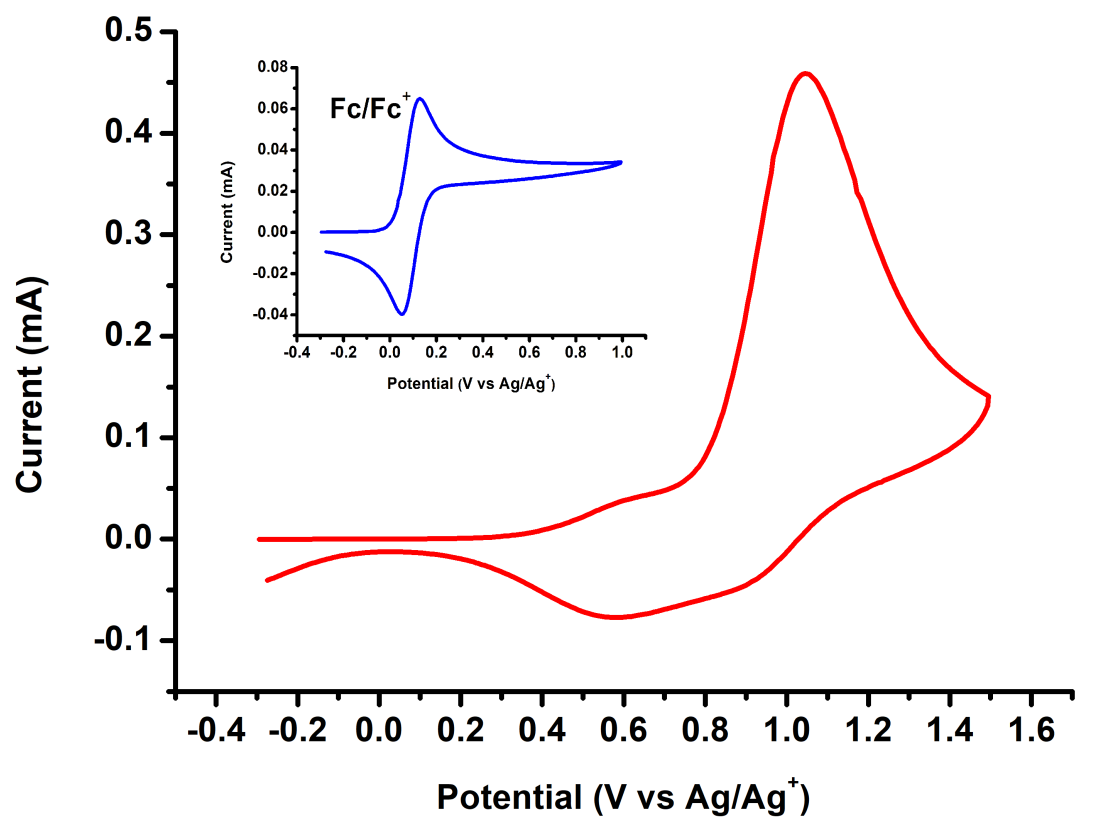

Figure S18: Film Cyclic Voltammetry of H-PyGNR in acetonitrile solution with 0.1 $\mathrm{M} \mathrm{Bu}_{4} \mathrm{NPF}_{6}$ as the supporting electrolyte with a scan rate of $50 \mathrm{mV} \mathrm{s}^{-1}$. 

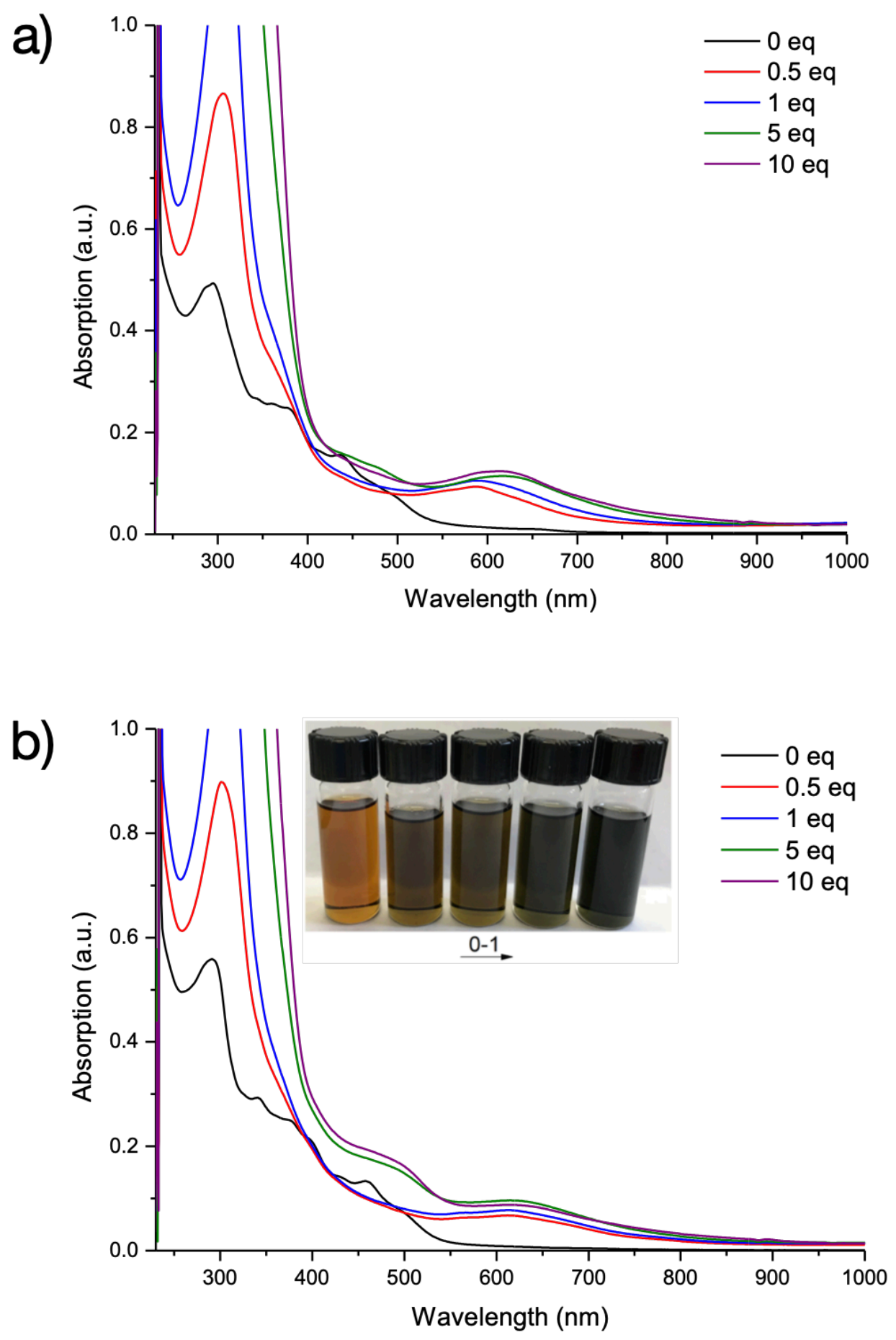

Figure S19: Changes of UV-vis-NIR spectra observed during chemical titration of (a) L-PyGNR and (b) H-PyGNR with TBPA. Inset in (b): Color changes (from orange to green) after adding different equivalents of TBPA into the H-PyGNR solution. 


\section{RAMAN SPECTROSCOPY}

\section{DFT calculations of Raman spectra}

We adopted molecular models of L-PyGNR and H-PyGNR comprising nine pyrrole units and explicit alkyl functionalization (C14 chains). We carried out DFT calculations with the B3LYP functional and the 6-31G(d,p) basis set. To ease the comparison of the simulated Raman spectra with the experimental counterparts we employed an empirical wavenumber scale factor of 0.98 , following the results of previous investigations on similar systems. ${ }^{3}$ We carried out with the Gaussian software ${ }^{4}$ standard full geometry optimization and off-resonance Raman calculations that are suitable for the comparison with experimental spectra recorded with a $1064 \mathrm{~nm}$ laser excitation. The calculation of the Raman response was carried out on a dedicated custom computer system equipped with 88 physical CPU cores (Intel Xeon E7-8880 v4, 2.20 GHz), $1024 \mathrm{~Gb}$ of RAM and $900 \mathrm{~Gb}$ of fast scratch storage (SSD drive).

We report in Figure S20 the simulated Raman spectra of the models of L-PyGNR and H-PyGNR. The spectra have been obtained by weighted sums of Lorentzian functions, with $\mathrm{FWHM}=10 \mathrm{~cm}^{-1}$, and weights given by the computed Raman intensities. 


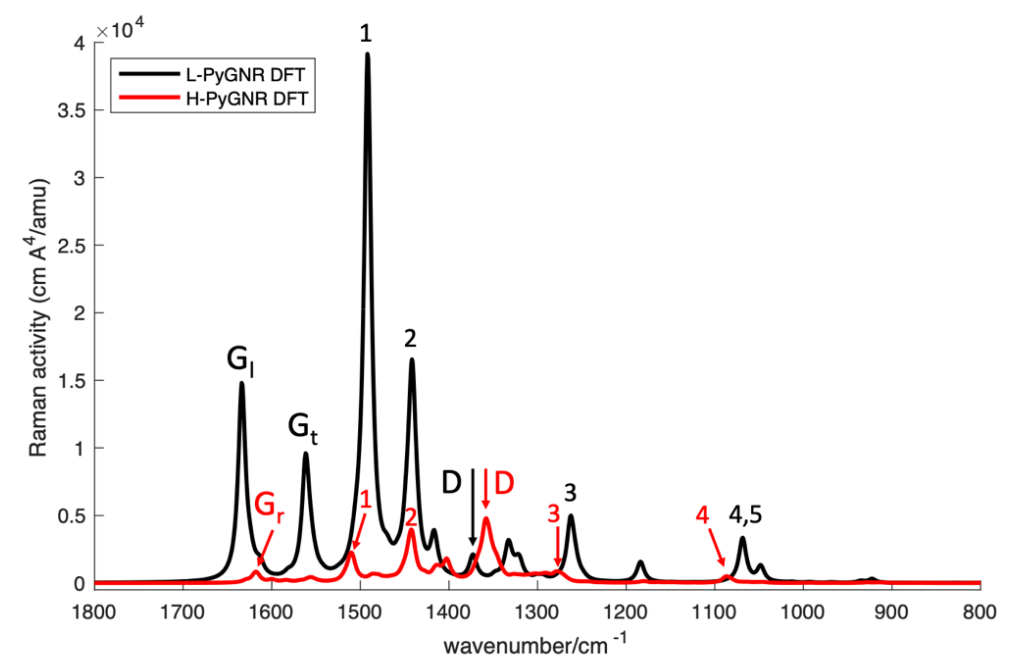

Figure S20: Simulated off-resonance Raman spectra of the models of L-PyHGNR and H-PyHGNR computed by DFT methods.

\section{Raman spectroscopy}

The reported FT-Raman spectra were acquired with the Nicolet NXR 9650 instrument equipped with a Nd:YVO4 laser (providing a $1064 \mathrm{~nm}$ excitation) and an InGaAs detector. The spectra were recorded on the powder sample of $\mathbf{H}$ - and L-PyGNR with the micro stage setup (spot size $\sim 50 \mu \mathrm{m}$ ).

\section{Assignment of the relevant Raman modes of H- and L-PyGNR}

\section{G modes}

The four modes reported below for the two PyGNRs show the characteristic ring stretching pattern expected for the G modes of graphene molecules. In such graphical representations the red arrows represent the nuclear displacements, and the green (blue) 
bonds are stretching (shrinking). In H-PyGNR the mode computed at $1649 \mathrm{~cm}^{-1}\left(\mathrm{G}_{\mathrm{r}}\right)$ exhibit nuclear displacements that occur in the radial direction (i.e., perpendicular to the helix axis); the mode computed at $1632 \mathrm{~cm}^{-1}\left(\mathrm{G}_{\mathrm{h}}\right)$ has nuclear displacements that follow the helical pattern. Such two modes have been labeled as radial and helical based on the relationship between the direction of the nuclear displacements of the ring stretching patterns and the helix. The G modes of L-PyGNR are computed at $1666 \mathrm{~cm}^{-}$ ${ }^{1}\left(\mathrm{G}_{\mathrm{l}}\right)$ and $1593 \mathrm{~cm}^{-1}\left(\mathrm{G}_{\mathrm{t}}\right)$. As shown in the graphical representation of both modes, the nuclear displacements of the carbon atoms in the $\mathrm{G}_{1}$ mode are overall parallel to the $\mathbf{L}$ PyGNR axis, whereas the nuclear displacements of the carbon atoms in the $\mathrm{G}_{\mathrm{t}}$ mode are overall orthogonal to the L-PyGNR axis. For this reason, such two modes have been labeled as longitudinal $\left(\mathrm{G}_{\mathrm{l}}\right)$ and transversal $\left(\mathrm{G}_{\mathrm{t}}\right)$. The displacement patterns of the $\mathrm{G}_{\mathrm{h}}$ mode of H-PyGNR and of the $\mathrm{G}_{1}$ mode of L-PyGNR are comparable: for this reason, they have been the subject of the analysis of the Raman activity of the G band (see below).
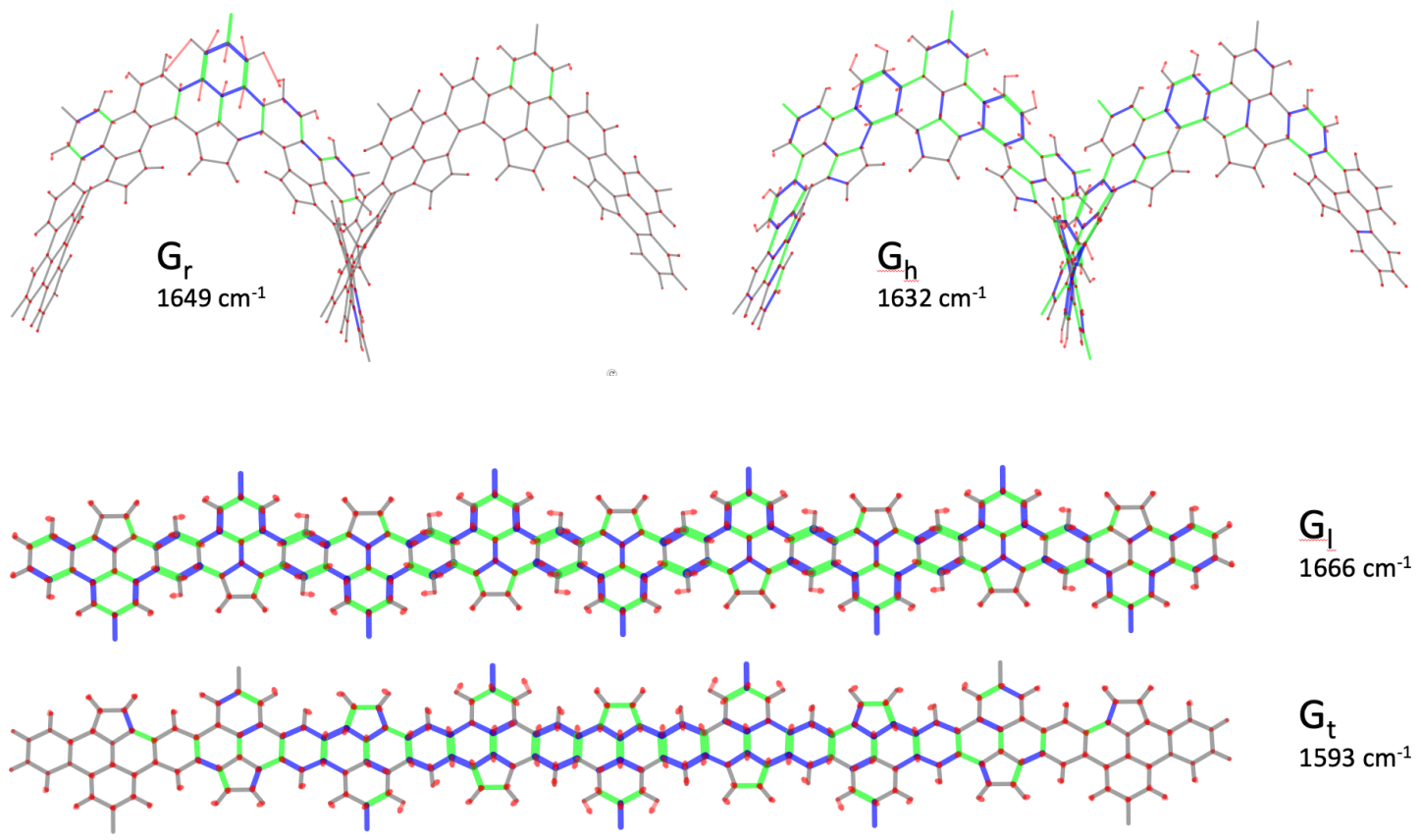


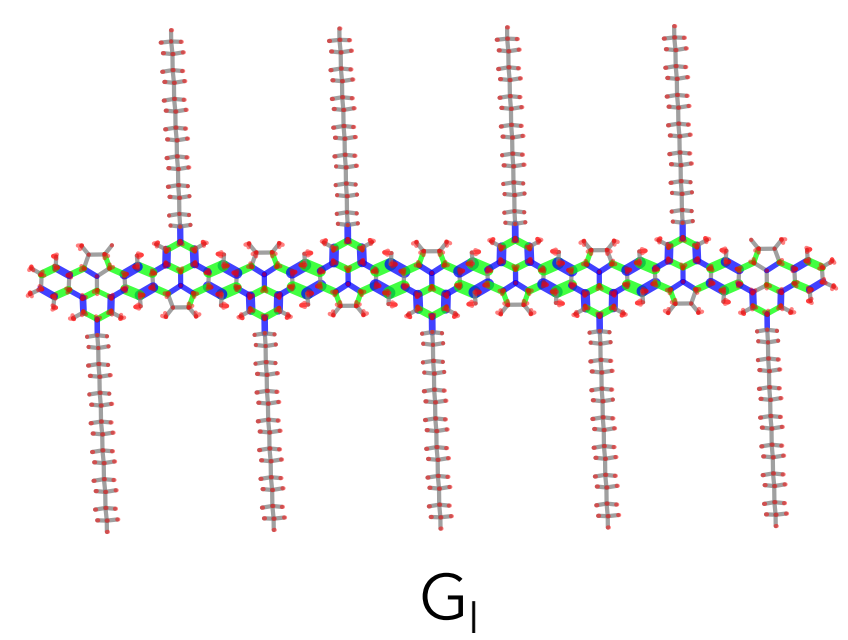

$1666 \mathrm{~cm}^{-1}$

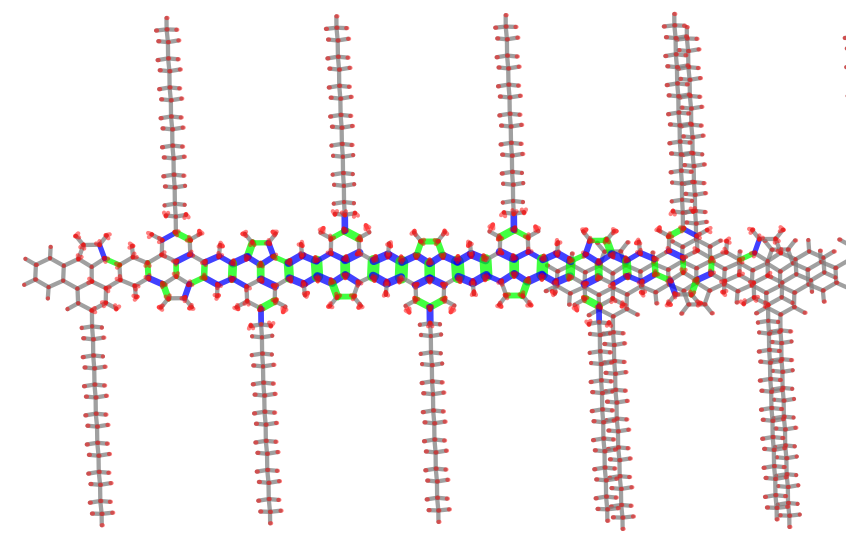

$\mathrm{G}_{\mathrm{t}}$

$1593 \mathrm{~cm}^{-1}$

Figure S21: Analysis of the G normal modes of H-PyGNR (top) and L-PyGNR (bottom).

\section{D modes}

The modes computed at $1386 \mathrm{~cm}^{-1}$ (H-PyGNR) and $1400 \mathrm{~cm}^{-1}$ (L-PyGNR) approximately display the collective ring-breathing pattern expected in the D modes of graphene molecules. Remarkably, the pyrrole moieties participate to the $\mathrm{D}$ mode.
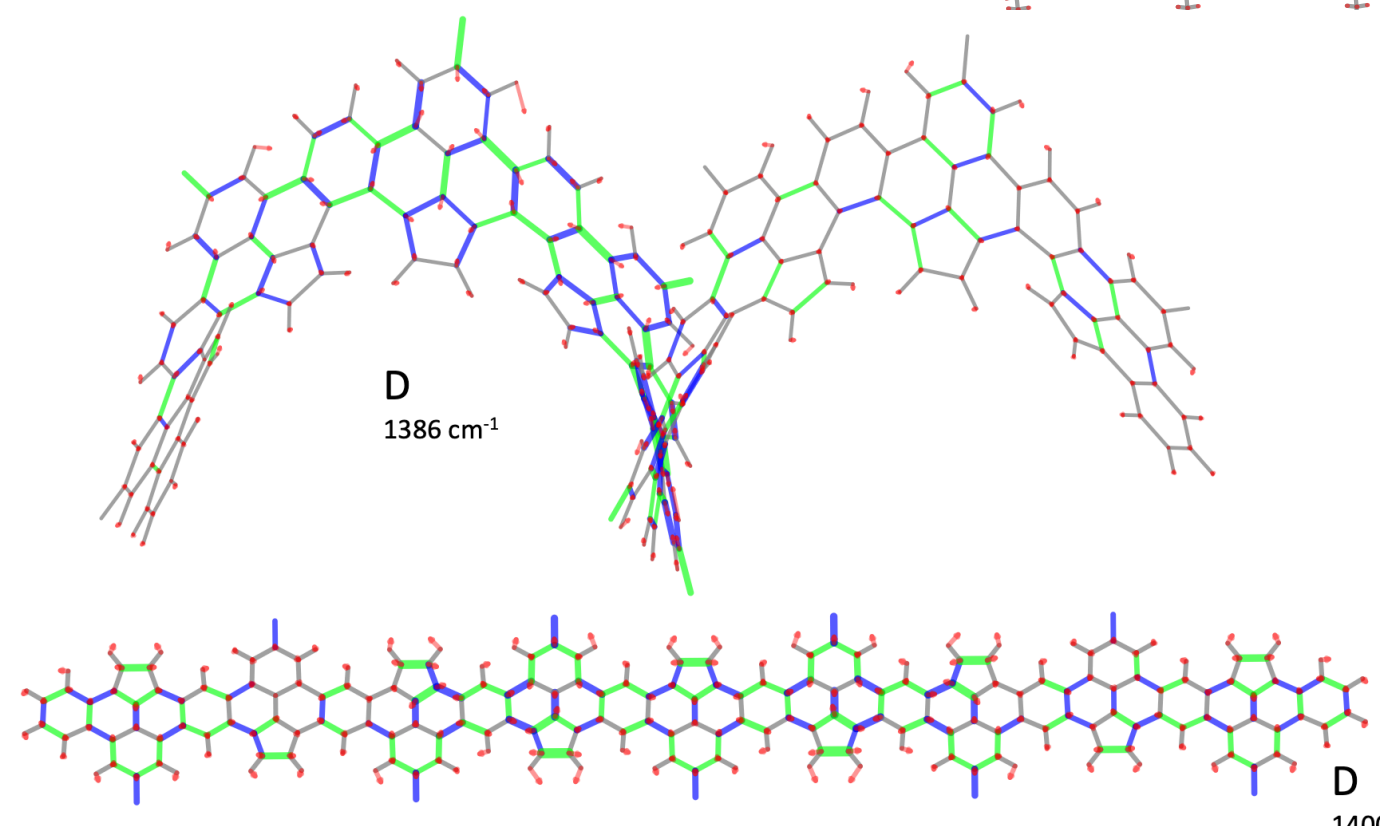
Figure S22: Analysis of the D normal modes of H-PyGNR (top) and L-PyGNR (bottom). For the sake of clarity, the alkyl chains have been hidden in the graphical representation (they do not contribute to the nuclear displacement pattern, as it can be seen in the representative example of L-PyGNR for which we also report the complete representation of the molecular structure).

\section{Other modes}

The Raman spectra of H-PyGNR and L-PyGNR display a few other interesting transitions. In both PyGRNs, the modes labeled 1,2 and 3 all display a collective CC stretching behavior with a noticeable participation of the pyrrole moieties that implies also significant $\mathrm{CN}$ stretching contributions. The modes labeled 4 are assigned, in both PyGNRs, to the breathing of the ring that bridges the monomer units. In the modes labeled 4, such breathing of the bridging ring occurs out-of-phase with respect to the noticeable $\mathrm{CC} / \mathrm{CN}$ stretching located on the pyrrole rings. Finally, a second feature close to the one labeled 4 is observed in both the experimental and simulated Raman spectrum of L-PyGNR. The associated mode 5 is assigned to the breathing of the bridging rings (similar to mode 4) and to the stretching of the CC bond of the pyrrole moieties that is parallel to the L-PyGNR axis. Such CC stretching happens out-of-phase with respect to the $\mathrm{CN}$ stretching at the pyrrole moieties. 

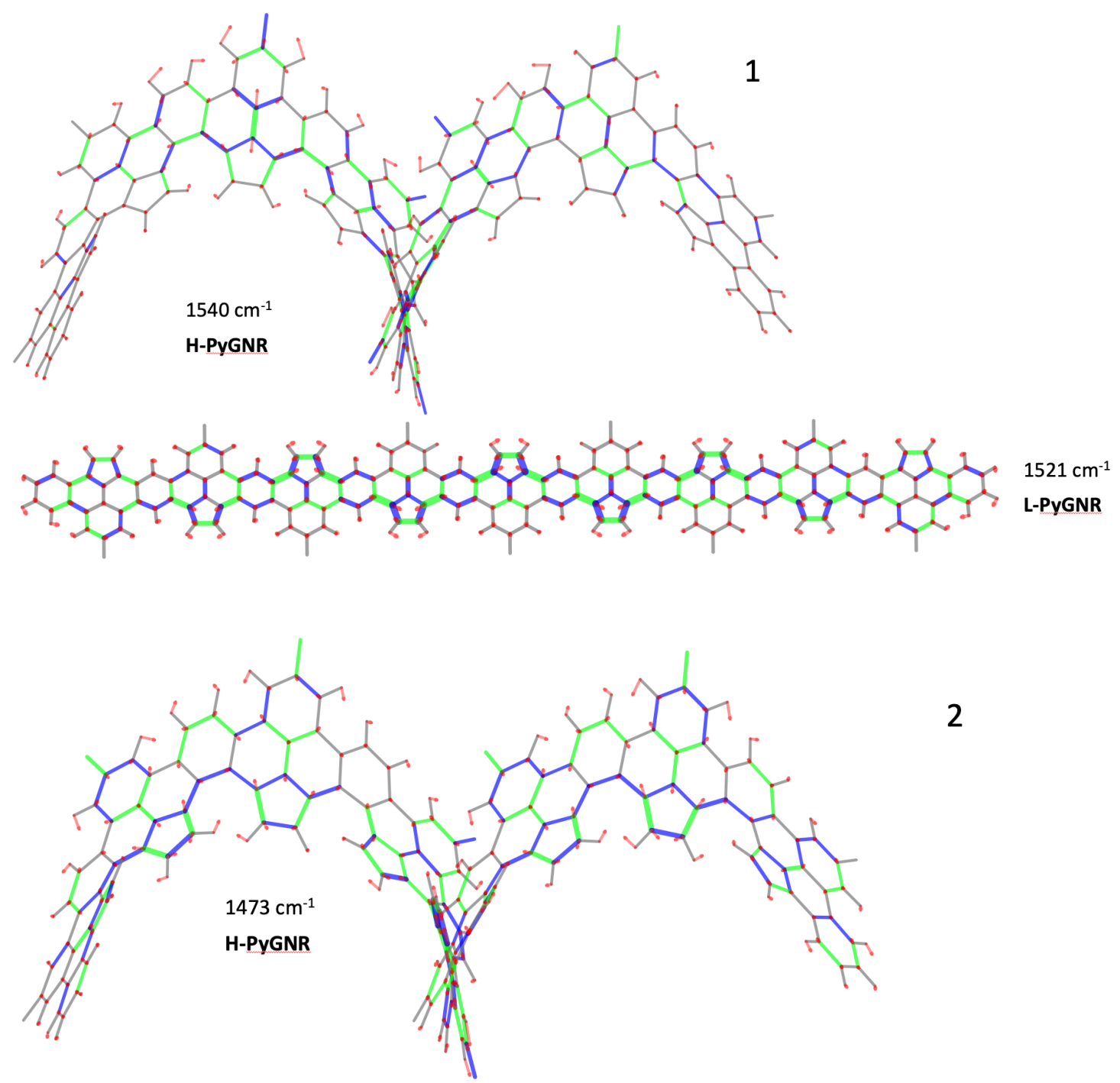

2

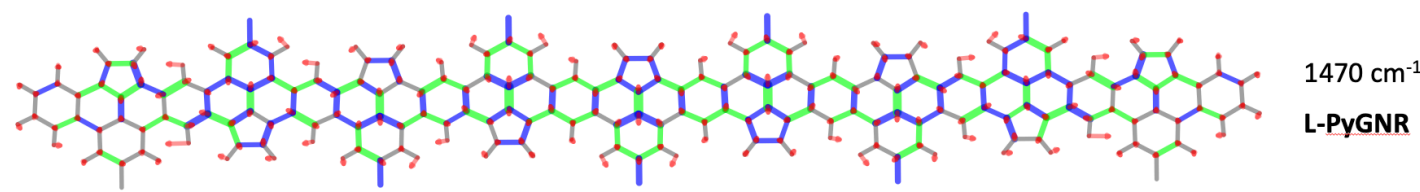

Figure S23: Analysis of other normal modes of H-PyGNR and L-PyGNR. For the sake of clarity, the alkyl chains have been hidden in the graphical representation. For the sake of clarity, the alkyl chains have been hidden in the graphical representation. 

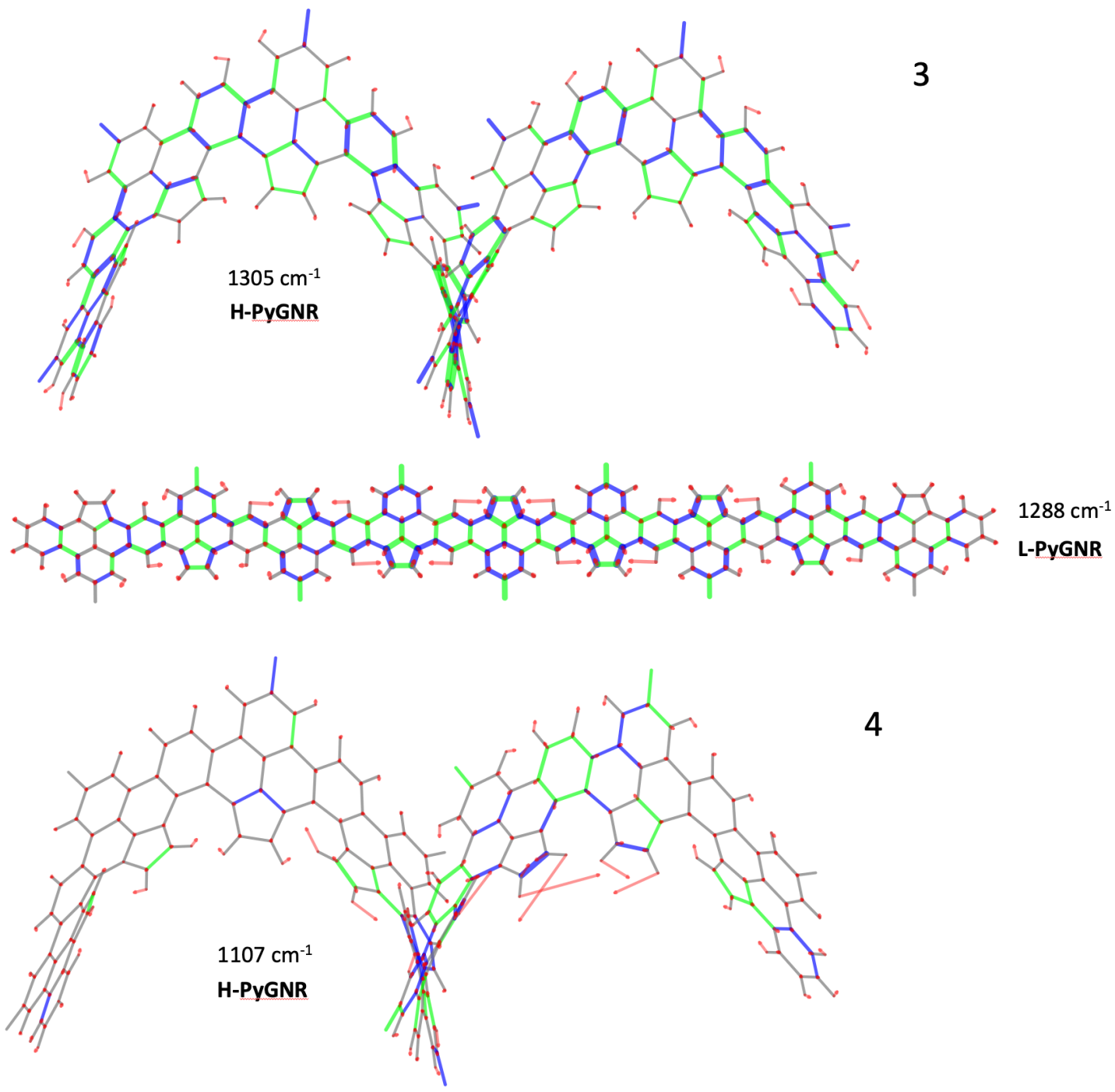

4

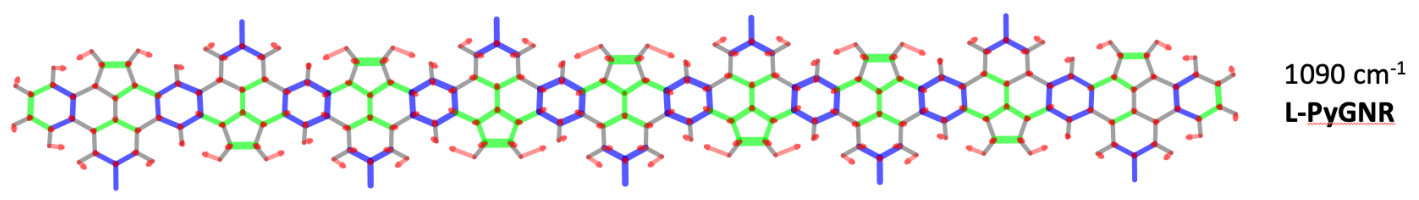

5

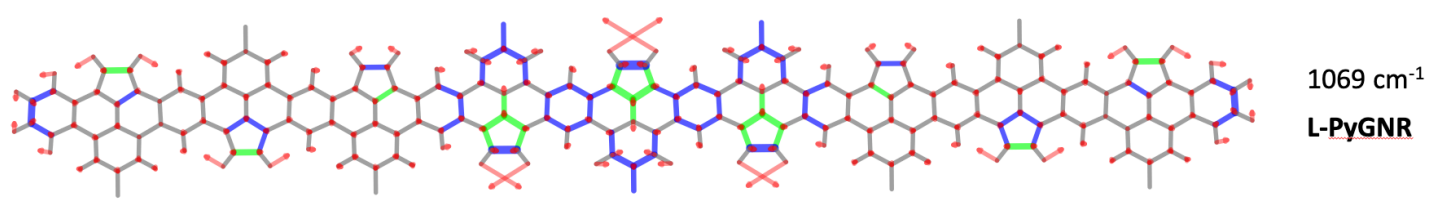

Figure S23 (continued): Analysis of other normal modes of H-PyGNR and L-

PyGNR. For the sake of clarity, the alkyl chains have been hidden in the graphical representation. 


\section{Empirical model of the longitudinal $G$ band intensity.}

The model considers as a building block the Raman polarizability derivatives of the $\mathrm{E}_{2 \mathrm{~g}}$ ring stretching modes of benzene (see Fig. S24).

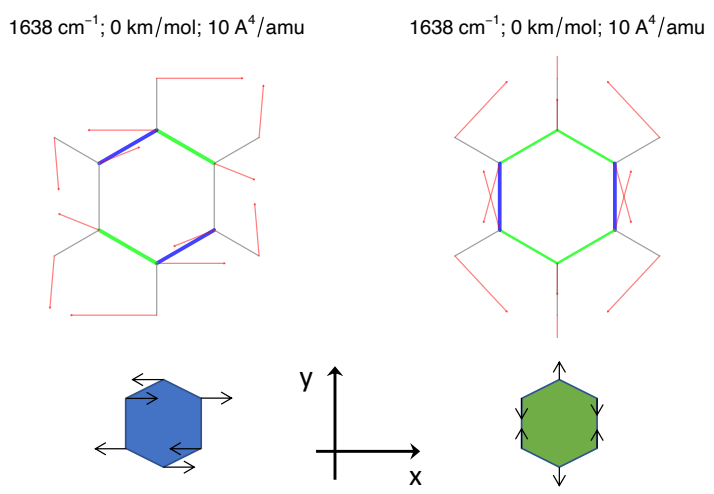

(1)

(2)

Figure S24. Nuclear displacement vectors of the doubly degenerate $\mathrm{E}_{2 \mathrm{~g}}$ ring stretching modes of benzene (after B3LYP/6-311G(d,p) calculations; green (blue) lines denote streching (shrinking) CC bonds; red lines are displacement vectors). The Cartesian reference used to represent the two Raman polarizability tensors (see text) is also reported, together with the simplified sketch of the nuclear displacement patterns that are used to describe the G modes of L-PyGNR and H-PyGNR (see text).

As expected, based on the character tables of the $\mathrm{D}_{6 \mathrm{~h}}$ point group, ${ }^{5}$ the Raman tensors of the two modes reported in Fig. S24 satisfy the following general expression:

$\frac{\partial \boldsymbol{\alpha}}{\partial q_{1}}=\boldsymbol{\alpha}_{1}=\left(\begin{array}{cc}0 & -a \\ -a & 0\end{array}\right) ; \quad \frac{\partial \boldsymbol{\alpha}}{\partial q_{2}}=\boldsymbol{\alpha}_{2}=\left(\begin{array}{cc}-a & 0 \\ 0 & a\end{array}\right)$ 
L-PyGNR G,

$1666 \mathrm{~cm}^{-1}$ (unscaled wavenumber value)
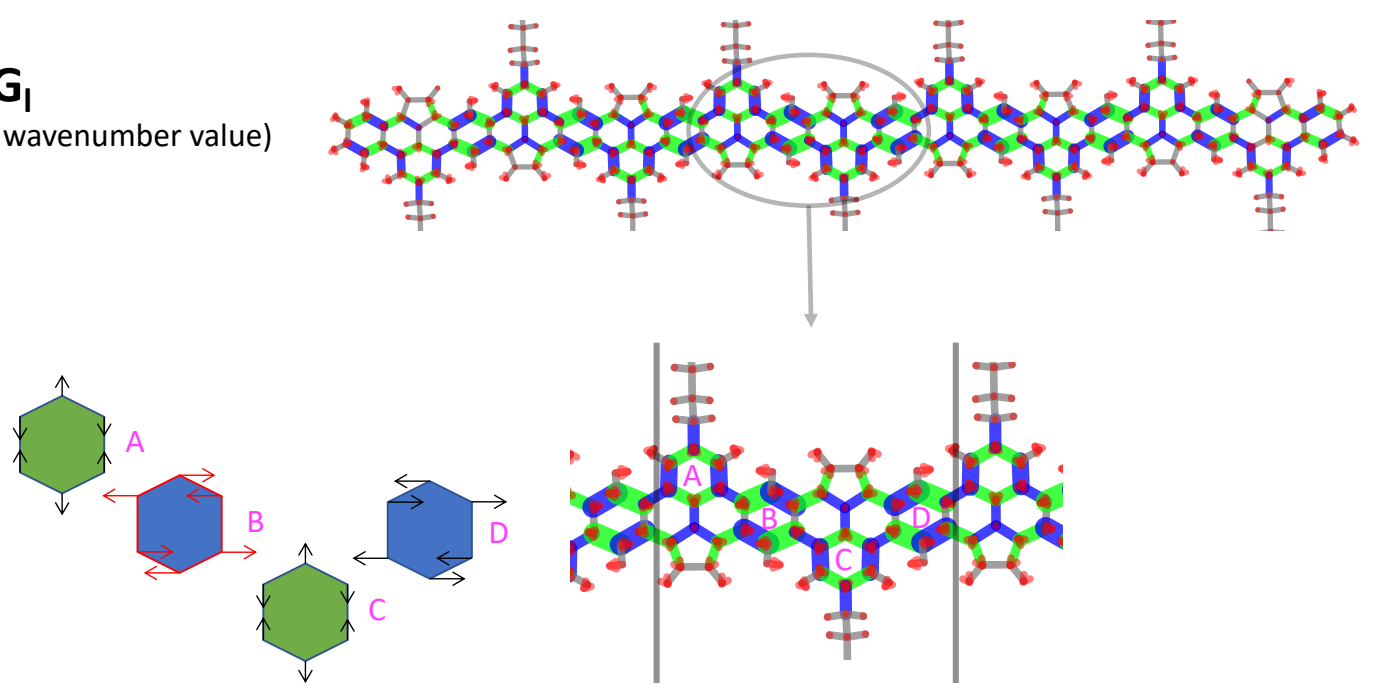

H-PyGNR $\quad G_{h}$

$1632 \mathrm{~cm}^{-1}$ (unscaled wavenumber value)

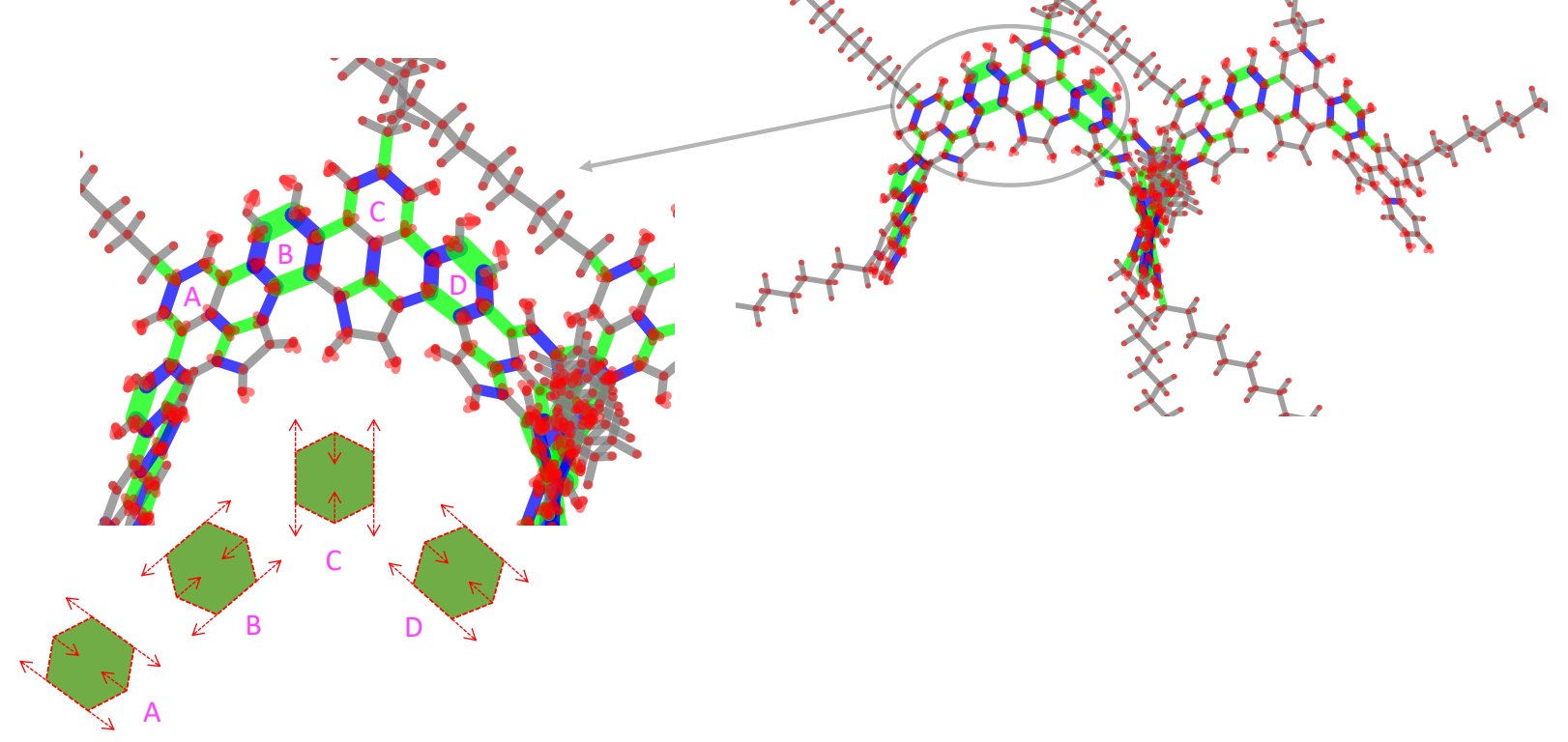

Figure S25. Analysis of the nuclear displacement patterns of the longitudinal $\left(\mathrm{G}_{\mathrm{l}}\right)$ and helical $\left(G_{h}\right)$ G modes of L-PyGNR and H-PyGNR. The displacement patterns of the four rings of the unit cells of the polymers are identified with the ring stretching modes of benzene (see Fig. S24 for the color codes). In some cases, the phase of the ring stretching pattern has to be inverted, as for the B ring of L-PyGNR, and all the rings of H-PyGNR. 
By visual inspection of the G modes of L-PyGNR and H-PyGNR (Fig. S25) one can identify the nuclear displacement patterns of the four six-membered rings that are present in the translational units of both polymers. Of course, to sum such four contributions, one must ensure that (where required) the local axes of the tensors in (1) match those required by the displacement pattern of the polymer. This is conveniently handled by a rotation matrix $\mathbf{R}(\theta)$ :

$\boldsymbol{R}(\theta)=\left(\begin{array}{cc}\cos (\theta) & -\sin (\theta) \\ \sin (\theta) & \cos (\theta)\end{array}\right)$

By acting on the polarizability derivative tensor $\left(\mathbf{R} \mathrm{d} \boldsymbol{\alpha} / \mathrm{dq}_{\mathrm{k}} \mathbf{R}^{\mathrm{t}}\right)$, the $\mathbf{R}(\theta)$ matrix aligns the local reference of benzene (Figure S24) to the one required by the vibrational structure of the polymer (Figure S25). This point is especially relevant to H-PyGNR. Figure S25 provides the graphical representation of the details that allow to derive the expressions of the Raman polarizability tensors of the translational units of L-PyGNR and H-PyGNR:

$$
\begin{gathered}
\frac{\partial \boldsymbol{\alpha}}{\partial q}=A+B+C+D=\boldsymbol{\alpha}_{2}+\left(-\boldsymbol{\alpha}_{1}\right)+\boldsymbol{\alpha}_{2}+\boldsymbol{\alpha}_{1}=2 \boldsymbol{\alpha}_{2} \\
(3-\text { L-PyGNR }) \\
\frac{\partial \boldsymbol{\alpha}}{\partial q}=A+B+C+D=\boldsymbol{R}\left(60^{\circ}\right)\left(-\boldsymbol{\alpha}_{2}\right) \boldsymbol{R}^{t}\left(60^{\circ}\right)+\boldsymbol{R}\left(120^{\circ}\right)\left(-\boldsymbol{\alpha}_{2}\right) \boldsymbol{R}^{t}\left(120^{\circ}\right)+ \\
\left(-\boldsymbol{\alpha}_{2}\right)+\boldsymbol{R}\left(60^{\circ}\right)\left(-\boldsymbol{\alpha}_{2}\right) \boldsymbol{R}^{t}\left(60^{\circ}\right)=\left(\begin{array}{cc}
-1 / 2 & \sqrt{3} / 2 \\
\sqrt{3} / 2 & 1 / 2
\end{array}\right) a \\
(4-\mathrm{H}-\mathrm{PyGNR})
\end{gathered}
$$

It is worth noticing that in Eqs. $(3,4)$ the sign of the tensor is also accommodated to match the displacement pattern of the polymer, as required when the phase of the ring stretching in Fig. S25 is opposite to the one in Fig. S24. By computing the intensity 
associated to the Raman tensors given by the expressions $(3,4)$ with well-established formulas one obtains the following Raman intensity ratio:

$$
\frac{\mathrm{I}_{\mathrm{G}(\mathrm{L}-\mathrm{PyGNR})}}{\mathrm{I}_{\mathrm{G}(\mathrm{H}-\mathrm{PyGNR})}}=4
$$




\section{TNT Titration experiments}

The GNRs were dissolved in THF at a concentration of $1.07 \times 10^{-5} \mathrm{M}$ for L-PyGNR, $1.22 \times 10^{-5} \mathrm{M}$ for H-PyGNR and TNT $\left(4.4 \times 10^{-6} \mathrm{M}\right.$ in acetonitrile) was added in 0.1 mL portion. A fluorescence spectrum was recorded after each addition. The spectra were corrected for the dilution upon addition of the TNT solution.
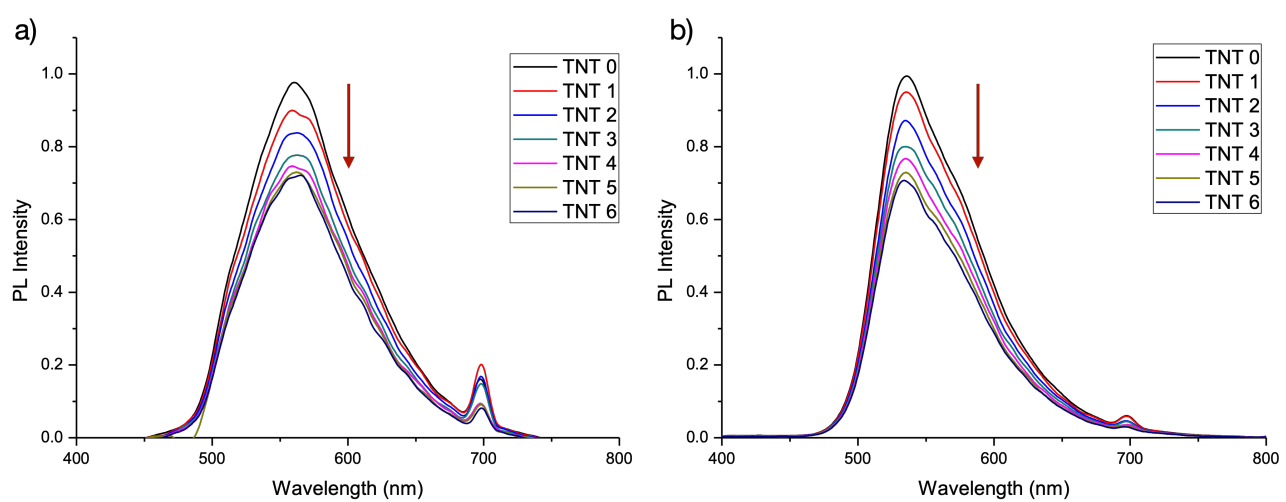

Figure S26. Fluorescence spectra of (a) L-PyGNR and (b) H-PyGNR in THF solution upon addition of TNT in acetonitrile. Polymer concentration: $1.07 \times 10^{-5} \mathrm{M}$ for L-PyGNR and $1.22 \times 10^{-5} \mathrm{M}$ for H-PyGNR.

a)

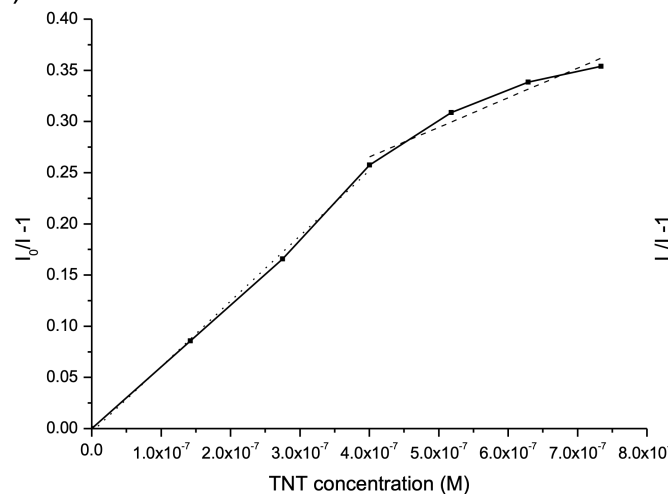

b)

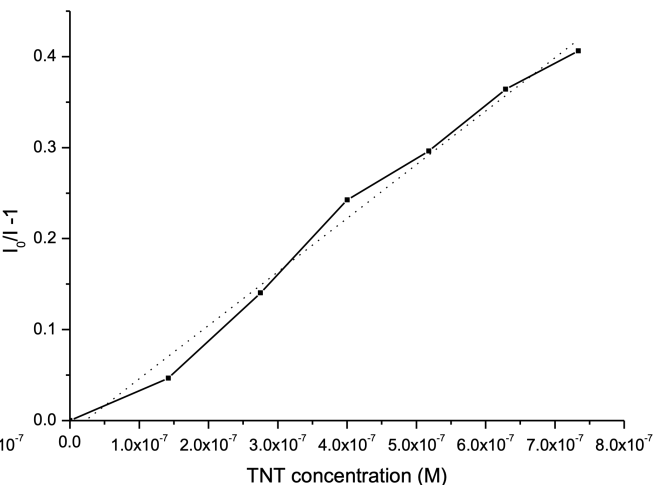

Figure S27. Stern-Volmer plots of the relative fluorescence intensity of (a) LPyGNR and (b) H-PyGNR vs TNT concentration. 


\section{FLUORESCENCE QUANTUM YIELDS}

Quantum yields for L-PyGNR and H-PyGNR were determined using Rhodamine B as the standard $\left(\phi_{\mathrm{F}}=0.94\right.$ in ethanol) using the following equation:

\section{$\boldsymbol{\Phi}_{\mathrm{F}}=\boldsymbol{\Phi}_{\mathrm{ST}}($ slope $\mathrm{GNR} /$ slopest $)\left(\eta^{2} \mathrm{GNR} / \eta^{2} \mathrm{ST}\right)$}

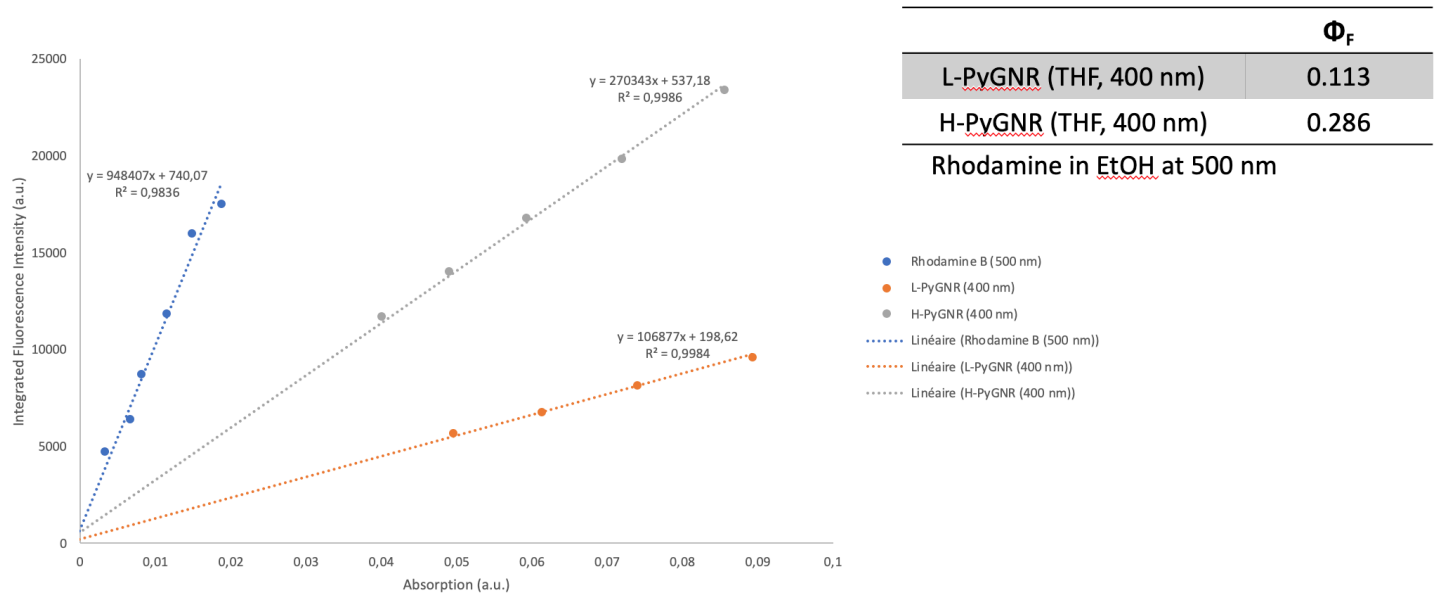




\section{DFT CALCULATIONS}

DFT calculations for the geometry optimization as well as frequency optimization of both H-PyGNR and L-PyGNR were carried out with Gaussian 09 suites $^{4}$ at the B3LYP/6-31G(d,p) level of theory.

Cartesian coordinates of the models of $\mathrm{H}$ - and L-PyGNR used for the simulation of the Raman spectra (B3LYP/6-31G(d,p) optimized structures)

\section{H-PyGNR}

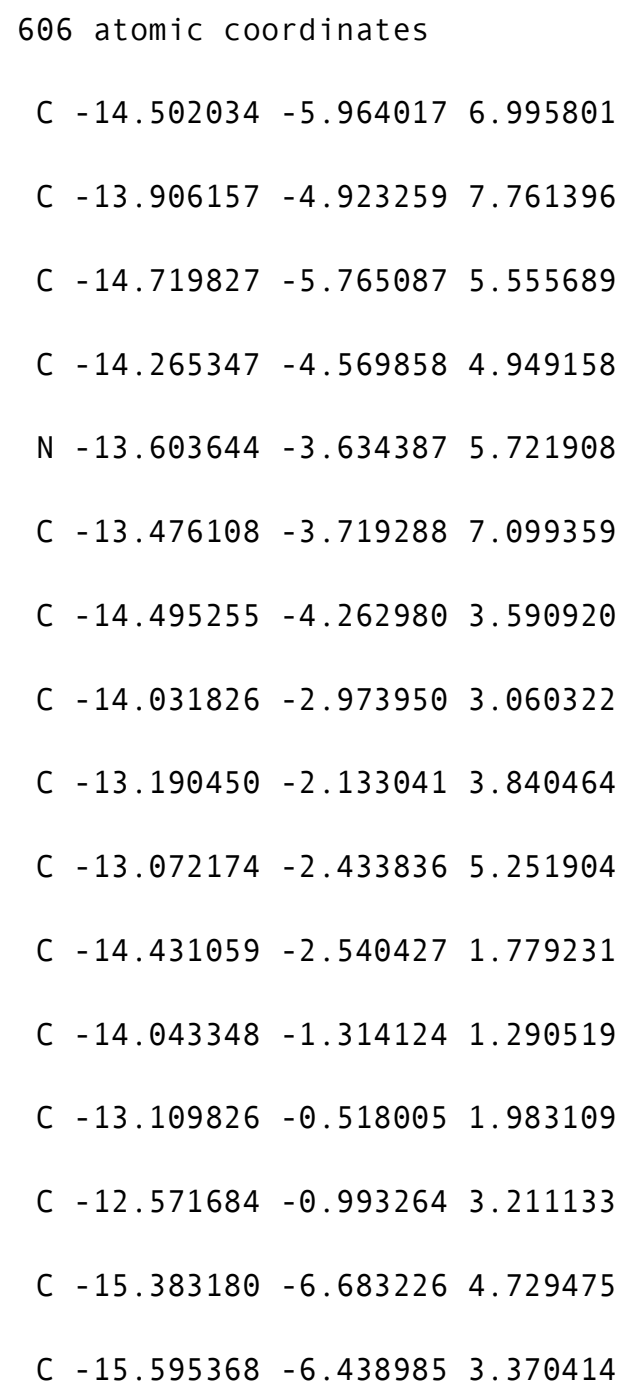


C $-15.153785-5.2334712 .820258$

C $-12.894515-2.5257397 .522025$

C $-12.655940-1.731206 \quad 6.389322$

C $-14.884287 \quad-7.144587 \quad 7.661603$

C $-14.702327 \quad-7.297472 \quad 9.027978$

C $-14.125916-6.262176 \quad 9.778231$

C $-13.732316-5.0930519 .150020$

H $-15.103327-3.1502311 .188136$

$\begin{array}{lllll}H & -15.75000 \odot & -7.614347 & 5.147925\end{array}$

C $-16.338473 \quad-7.446251 \quad 2.518134$

H $-15.314041-5.062024 \quad 1.761503$

H $-12.666074 \quad-2.261533 \quad 8.544342$

H $-12.235490 \quad-0.739456 \quad 6.389663$

H $-15.329169-7.9589297 .100745$

H $-15.006227-8.219784 \quad 9.513492$

H $-13.982389-6.377598 \quad 10.848386$

H $-13.275843-4.294565 \quad 9.726265$

C $-12.698083 \quad 0.786975 \quad 1.456691$

C $-11.583919 \quad 1.430260 \quad 2.031937$

N $-10.908033 \quad 0.788805 \quad 3.047312$

C $-11.371273-0.349508 \quad 3.705511$

C $-13.367816 \quad 1.468691 \quad 0.429032$

C $-12.944611 \quad 2.721904 \quad-0.021091$

C $-11.826907 \quad 3.3171210 .571746$

C $-11.125182 \quad 2.696718 \quad 1.615718$

C $-10.384221-0.668784 \quad 4.644806$

C $-9.672353 \quad 1.1949213 .549549$

C $-9.359850 \quad 0.282045 \quad 4.563204$

C $-9.1141212 .447306 \quad 3.083829$ 
C $-9.936891 \quad 3.264979 \quad 2.260104$

C $-7.821394 \quad 2.948494 \quad 3.479667$

C $-9.594000 \quad 4.618925 \quad 2.073488$

C $-8.489417 \quad 5.161234 \quad 2.689716$

C - $-7.579743 \quad 4.347920 \quad 3.394302$

H $-14.421365-0.986408 \quad 0.329351$

H $-14.2501951 .027584-0.022209$

C $-13.711992 \quad 3.450434-1.104571$

H $-11.487595 \quad 4.274604 \quad 0.190914$

H $-10.400885-1.517150 \quad 5.307656$

H $-8.485410 \quad 0.317703 \quad 5.190796$

C $-6.714914 \quad 2.104153 \quad 3.879179$

H $-10.239538 \quad 5.260898 \quad 1.485966$

H $-8.289282 \quad 6.220290 \quad 2.578579$

C -6.3976614 .9290524 .039026$

C $-5.3845124 .066376 \quad 4.505702$

$N-5.536452 \quad 2.710430 \quad 4.311019$

C $-4.226618 \quad 4.523928 \quad 5.165434$

C $-3.224780 \quad 3.543653 \quad 5.595645$

C $-3.285994 \quad 2.205622 \quad 5.115362$

C $-4.530109 \quad 1.767876 \quad 4.516990$

C $-2.192629 \quad 3.909098 \quad 6.482801$

C $-1.2620712 .987466 \quad 6.905410$

C $-1.212960 \quad 1.696106 \quad 6.343578$

C $-2.152187 \quad 1.342496 \quad 5.334647$

C $-6.428276 \quad 0.736608 \quad 3.800545$

C $-5.104765 \quad 0.529633 \quad 4.207697$

C $-6.219826 \quad 6.301475 \quad 4.265025$

C $-5.080329 \quad 6.802240 \quad 4.902883$ 
C $-4.098137 \quad 5.910770 \quad 5.340664$

H $\quad-2.163770 \quad 4.913043 \quad 6.889339$

H $-0.522054 \quad 3.283196 \quad 7.639512$

C $-0.217188 \quad 0.717909 \quad 6.793305$

C $-1.858047 \quad 0.175020 \quad 4.530277$

H $-7.107976-0.027294 \quad 3.462369$

H $-4.615756-0.426247 \quad 4.290405$

H $-6.992610 \quad 7.000122 \quad 3.962164$

C $-4.905017 \quad 8.295596 \quad 5.084674$

H $\quad-3.208247 \quad 6.312394 \quad 5.813242$

N $-0.776319-0.625887 \quad 4.891376$

C $-0.035146-0.460162 \quad 6.041339$

C $-0.538622-1.613129 \quad 3.936776$

C $0.454135-2.627365 \quad 4.224438$

C $1.011041-2.645903 \quad 5.533513$

C $0.873725-1.474417 \quad 6.404858$

C $0.839973 \quad-3.661918 \quad 3.297696$

C $1.409161-4.859713 \quad 3.813806$

C $1.820027-4.900415 \quad 5.161123$

C $1.696265-3.7960115 .973143$

C $-2.304029-0.324848 \quad 3.301424$

C $-1.513099 \quad-1.425660 \quad 2.949787$

C $0.555134 \quad 0.857223 \quad 7.956746$

C $1.627141-1.267358 \quad 7.569618$

C $1.476048-0.117435 \quad 8.350273$

C $0.771877-3.522181 \quad 1.858058$

C $1.560624-6.032814 \quad 2.946947$

H $2.296181-5.7921195 .551268$

H $2.081322 \quad-3.838247 \quad 6.985141$ 

H -3.1092640 .0839582 .714516$
H $-1.645189-2.0404862 .075446$
H $\odot .430158 \quad 1.734063 \quad 8.583023$
H 2.369504 -2.000720 7.866229
C $2.275935 \quad 0.048703 \quad 9.625361$
C $1.391230-5.875709 \quad 1.556769$
N $1.117971-4.616597 \quad 1.067470$
C $1.485805-6.944593 \quad 0.642274$
C $1.327327-6.666400-0.788986$
C $1.354570-5.323500-1.257861$
C $1.153759-4.272695-0.282350$
C $1.161861-7.714371-1.716308$
C $1.016900-7.454698-3.060361$
C $1.190040-6.152471-3.570349$
C $1.494060-5.090911-2.673410$
C $0.591782-2.4565810 .968442$
$\begin{array}{llll}\text { C } & 0.805447 & -2.918297 & -0.336134\end{array}$
C $1.831020 \quad-7.328425 \quad 3.413676$
C $1.944807-8.4158292 .543262$
C $1.771912-8.211784 \quad 1.170940$
H $1.089844-8.736836-1.364777$
H $0.828542-8.277382-3.739961$
C $1.059810-5.884557-5.006354$
C $2.018635-3.866719-3.241179$
H $\odot .350354-1.4439901 .244614$
H $0.699987-2.334186-1.234890$
H $1.933910 \quad-7.505308 \quad 4.478995$
C $2.303233-9.7895323 .070466$
H $1.885404-9.0592260 .503060$ 

N 2.055644 $-3.739246-4.628662$
C $1.500869-4.643171-5.508867$
C $2.724936-2.577857-5.010519$
C $2.728180-2.211160-6.411178$
C $1.910202-2.973516-7.290928$
C $1.396654-4.280198-6.866995$
C $3.433596-1.070816-6.939708$
C $2.993445-0.507331-8.169664$
C $2.072616-1.222798-8.960972$
C $1.607920-2.457092-8.566897$
C $2.697110-2.749245-2.741493$
C $3.109930-1.954924-3.817790$
C $0.483074-6.775000 \quad-5.923827$
C $0.366351-6.461195-7.281297$
C $0.827553-5.223204-7.736551$
H $1.765933-0.825753-9.921379$
$\begin{array}{llll}H & 0.949600 & -3.008287 & -9.227839\end{array}$
H $0.090396-7.724711-5.576233$
C $-0.218783-7.466973-8.250452$
H $3.621615-1.010494-3.740732$
C $4.623964-0.509272-6.337041$
C $3.487829 \quad 0.807993-8.590775$
H $\odot .753176-5.001232-8.795773$
H $2.888373-2.545711-1.701456$
C $4.578009 \quad 1.377411 \quad-7.901344$
N $5.163825 \quad 0.651486-6.886748$
C $5.101690 \quad 2.650752-8.203007$
C $6.254056 \quad 3.139394 \quad-7.438544$
C $6.996502 \quad 2.242055-6.621478$ 
C $6.377720 \quad 0.977290 \quad-6.284473$

C $6.6406894 .493451-7.498939$

C $7.7056324 .959908-6.761341$

C $8.5414164 .072721-6.053989$

C $8.2668312 .677663-6.098919$

C $6.599741-0.014855-5.322365$

C $5.541364-0.930380-5.367694$

C $4.4974193 .355989-9.254807$

C $2.919527 \quad 1.570144 \quad-9.622337$

C $3.4132182 .832558-9.964601$

H $6.0548795 .193699-8.082733$

H $7.9346996 .019025-6.774285$

C $9.6741364 .568145-5.264966$

C $9.323126 \quad 1.776207 \quad-5.691462$

H $7.435600-0.054376-4.644462$

H $5.454816-1.821637-4.769167$

H $4.8924464 .322551-9.549226$

H $2.062157 \quad 1.185913-10.164662$

C $2.752202 \quad 3.638606-11.063064$

N $10.4757762 .315461-5.124165$

C $10.630110 \quad 3.644802-4.794675$

C $11.447672 \quad 1.336003 \quad-4.928401$

C $12.648877 \quad 1.692148 \quad-4.200712$

C $12.6898812 .978371-3.594314$

C $11.7362104 .014729-4.003333$

$\begin{array}{llll}\text { C } & 13.749874 & 0.789208 & -3.978743\end{array}$

C $14.6201861 .028454-2.879338$

C $14.5413902 .262708-2.202213$

C $13.655013 \quad 3.236879-2.600928$ 
C $10.876996 \quad 0.142425-5.385946$

C $9.590267 \quad 0.413854 \quad-5.866955$

C $11.8649425 .374988-3.685201$

C $9.8516655 .911111-4.899616$

C $10.932809 \quad 6.323796-4.115661$

C $14.075258-0.313780-4.858093$

C $15.597703 \quad 0.011460-2.469341$

H $15.227673 \quad 2.477654-1.392132$

H $13.6651894 .196820-2.098468$

H $11.343806-0.827475-5.353917$

H $8.922413-0.301746-6.316645$

H $12.7170715 .713149-3.105148$

H $9.1219336 .652426-5.207844$

C $11.0595927 .769347-3.681860$

C $15.815630-1.106570-3.302528$

N $15.081835-1.197107-4.469966$

C $15.318494-2.135147-5.462209$

C $16.277916-3.179188-5.212717$

C $16.989128-3.192197-3.980322$

C $16.773223-2.107148-3.012398$

C $16.510734-4.195869-6.161108$

C $17.416032-5.211827-5.906839$

C $18.111581-5.238108-4.689258$

C $17.897581-4.242855-3.747407$

C $13.720634-0.689192-6.159672$

C $14.477519-1.813698-6.525857$

C $16.3285780 .068649-1.273026$

C $17.478871-1.978785-1.807427$

C $17.258778-0.915333-0.928708$ 

H $15.963776-4.178801-7.098427$
H $17.581837-5.988454-6.647468$
H $18.817766-6.036017-4.480962$
H $18.445211-4.284019-2.812464$
H $12.995699-0.185917-6.777477$
H $14.418179-2.342433-7.466121$
H $16.1564340 .882381-0.576976$
H $18.219588-2.723683-1.537446$
C $18.043182-0.812336 \quad 0.362574$
H $18.331439-1.817878 \quad 0.693510$
H $17.398700-0.402294 \quad 1.150634$
C $19.309546 \quad 0.059266 \quad 0.248120$
H $19.942776-0.332129-0.559176$
C $20.113211 \quad 0.118198 \quad 1.552211$
H $19.0215311 .073917-0.057946$
H $20.405906-0.9014631 .841120$
H $19.467062 \quad 0.486560 \quad 2.361932$
C $21.366050 \quad 0.998678 \quad 1.465130$
H $22.000726 \quad 0.647091 \quad 0.639334$
C $22.186512 \quad 1.0190012 .760675$
H $21.071674 \quad 2.025042 \quad 1.203895$
H $22.488829-0.007653 \quad 3.012212$
H $21.548284 \quad 1.356709 \quad 3.589730$
C $23.432890 \quad 1.909684 \quad 2.687512$
H $24.064048 \quad 1.5827191 .848839$
C $24.263291 \quad 1.906071 \quad 3.976801$
H $23.129762 \quad 2.940087 \quad 2.453078$
H $24.571011 \quad 0.875718 \quad 4.205675$
H $23.6304522 .225193 \quad 4.817283$ 
C 25.5060492 .8023713 .911146

H $26.1346372 .489505 \quad 3.065163$

C $26.342575 \quad 2.785135 \quad 5.196351$

H $25.197913 \quad 3.834726 \quad 3.692191$

H 26.6531311 .7528515 .412335

H $25.713254 \quad 3.093914 \quad 6.043316$

C $27.583438 \quad 3.684299 \quad 5.134287$

H $28.210383 \quad 3.378820 \quad 4.284390$

C $28.423560 \quad 3.6601696 .417025$

H $27.272625 \quad 4.717560 \quad 4.923498$

H $28.7355542 .626940 \quad 6.626440$

H $27.796301 \quad 3.963792 \quad 7.267411$

C $29.663398 \quad 4.560574 \quad 6.356542$

H $30.290658 \quad 4.258585 \quad 5.505452$

C 30.5054404 .5345607 .638035

H $29.352098 \quad 5.594566 \quad 6.149277$

H 30.8171693 .5016297 .844601

H $29.878908 \quad 4.836606 \quad 8.488373$

C 31.7412115 .4367177 .568645

H $32.404727 \quad 5.137238 \quad 6.749343$

H $32.320537 \quad 5.3963518 .496825$

H 31.4594426 .4820227 .397898

H $10.647996 \quad 8.427165-4.457589$

H $12.1204768 .031855-3.583071$

C $10.343698 \quad 8.051304-2.345932$

H $9.2799117 .800025 \quad-2.451818$

C $10.4862349 .499473-1.862970$

H $10.7391187 .369456-1.581247$

H $10.09603110 .182867-2.630669$ 
H $11.552733 \quad 9.743500 \quad-1.754193$

C $9.7665749 .760209-0.533950$

H $8.6972629 .534283-0.651396$

C $9.92695811 .192479-0.009320$

H 10.1413879 .0557220 .222198

H $9.55396611 .901608-0.762054$

H $10.99635611 .416187 \quad 0.113244$

C $9.202474 \quad 11.434534 \quad 1.320484$

H $8.13086011 .225200 \quad 1.192513$

C 9.37832212 .8542291 .873344

H $9.563685 \quad 10.710357 \quad 2.064695$

H 9.01764013 .5816391 .132086

H $10.449978 \quad 13.062123 \quad 2.003864$

C $8.651977 \quad 13.083538 \quad 3.204379$

H $7.578858 \quad 12.885628 \quad 3.070602$

C $8.838896 \quad 14.494538 \quad 3.775509$

H $9.004683 \quad 12.346347 \quad 3.939858$

H $8.486090 \quad 15.233760 \quad 3.042158$

H 9.91206614 .6916213 .910289

C $8.112194 \quad 14.715828 \quad 5.107698$

H 7.03819214 .5246394 .971134

C $8.305693 \quad 16.121578 \quad 5.689447$

H $8.460340 \quad 13.970985 \quad 5.837613$

H 7.95726016 .8674814 .960726

H $9.379757 \quad 16.312410 \quad 5.826276$

C 7.57927816 .3387907 .022272

H 6.50458616 .1506726 .885623

C 7.77481117 .7422627 .608864

H 7.92563815 .5913207 .750554 
H $7.427502 \quad 18.4894906 .882313$

H $8.848476 \quad 17.930278 \quad 7.745575$

C $7.046540 \quad 17.948667 \quad 8.940299$

H $5.96632317 .801156 \quad 8.828002$

H $7.204653 \quad 18.9588199 .331932$

H $7.397987 \quad 17.2395269 .698474$

H 2.393638 2.961967 -11.849223

H $3.495505 \quad 4.293508-11.534838$

C $1.5721684 .494646-10.562237$

H $0.8348353 .839612-10.079155$

C $0.8941965 .300350-11.676418$

H $1.9309025 .174873-9.778205$

H $0.5454734 .613033-12.460612$

H $1.636814 \quad 5.953648-12.156628$

C $-0.285573 \quad 6.148155-11.185485$

H $-1.025343 \quad 5.494154 \quad-10.702368$

C $-0.970106 \quad 6.949856-12.299394$

H $\odot .0635886 .837489-10.403579$

H $-1.316947 \quad 6.259774 \quad-13.081898$

H $-0.230827 \quad 7.605366-12.781616$

C $-2.152720 \quad 7.794286-11.809729$

H $-2.890528 \quad 7.138551-11.325682$

C $-2.8402628 .592945-12.923909$

H $-1.805827 \quad 8.485787 \quad-11.028561$

H $\quad-3.186091 \quad 7.901165-13.705370$

H $-2.1028619 .249557-13.407529$

C $-4.0243329 .435516-12.434546$

H $\quad-4.761024 \quad 8.778773-11.950087$

C $-4.713418 \quad 10.232847-13.548720$ 


$$
\begin{aligned}
& \text { H }-3.67846910 .127923-11.653681 \\
& \text { H }-5.0588899 .540377 \quad-14.329728 \\
& \text { H }-3.97692810 .890003-14.032990 \\
& \text { C }-5.89803811 .074542-13.059183 \\
& \text { H }-6.634372 \quad 10.417272-12.574870 \\
& \text { C }-6.587575 \quad 11.871929-14.173027 \\
& \text { H }-5.55255211 .766954-12.278145 \\
& \text { H }-6.93302611 .179544-14.954155 \\
& \text { H } \quad-5.851219 \quad 12.529296-14.657271 \\
& \text { C }-7.77212912 .713466-13.683578 \\
& \text { H }-8.509676 \quad 12.056747-13.200035 \\
& \text { C }-8.461498 \quad 13.512070-14.796653 \\
& \text { H }-7.427658 \quad 13.406092-12.902060 \\
& \text { H }-8.807024 \quad 12.820423-15.577097 \\
& \text { H } \quad-7.724818 \quad 14.168439-15.279781 \\
& \text { C }-9.64247314 .350325-14.298484 \\
& \text { H }-10.413616 \quad 13.718086-13.843726 \\
& \text { H }-10.11078514 .909334-15.115182 \\
& \text { H }-9.32236015 .074640-13.540729 \\
& \text { C } 0.814561-8.485020-8.772632 \\
& \text { H }-0.662554 \quad-6.938314 \quad-9.103181 \\
& \text { H }-1.038704-8.010226-7.763425 \\
& \text { H } 1.640442 \quad-7.943300 \quad-9.252571 \\
& \text { C } 0.217248-9.496129-9.757988 \\
& \text { H } 1.256824-9.016265-7.919261 \\
& \text { H }-0.215878-8.956989-10.612644 \\
& \text { H }-0.620510-10.021098-9.276853 \\
& \text { C } 1.232044-10.526091-10.269807 \\
& \text { H } 2.075030-10.001830-10.741831
\end{aligned}
$$



C $0.635874-11.527545-11.266659$
H $1.656439-11.072417-9.415565$
H $0.220928-10.980238-12.125066$
H $-0.214667-12.043115-10.798104$
C $1.643153-12.569243-11.769158$
H $2.498227-12.054635-12.230263$
C $1.047180-13.561563-12.775178$
H $2.050961-13.122746-10.911337$
H $0.646728-13.007562-13.636190$
H $\odot .186573-14.069711-12.316998$
C $2.048934-14.611966-13.270467$
H $2.912910-14.104633-13.723045$
C $1.453184-15.597397-14.283383$
H $2.443956-15.170626-12.409975$
H $1.063622-15.038503-15.146235$
H $0.585220-16.099954-13.832985$
C $2.450854-16.654190-14.773208$
H $3.320994-16.152327-15.220061$
C $1.855124-17.635296-15.790332$
H $2.836848-17.215997-13.910657$
H $1.473059-17.073482-16.654674$
H $0.982116-18.133579-15.344901$
C $2.849377-18.696942-16.276014$
H $3.723658-18.200266-16.720942$
C $2.253412-19.676771-17.294276$
H $3.230264-19.260573-15.412189$
H $1.875718-19.113956-18.158772$
H $1.378636-20.171354-16.850348$
C $3.250966-20.736644-17.770972$ 


$$
\begin{aligned}
& \text { H } 4.120509-20.275082-18.252688 \\
& \text { H } 2.794897-21.420323-18.494430 \\
& \text { H } 3.620531-21.338236-16.932685 \\
& \text { H }-14.215986 \quad 2.722081-1.751794 \\
& \text { H }-13.0099193 .999335-1.745112 \\
& \text { C - } 14.756415 \quad 4.437016-0.545612 \\
& \text { H }-15.457933 \quad 3.889142 \quad 0.097551 \\
& \text { C }-15.5308715 .184184-1.637366 \\
& \text { H }-14.249777 \quad 5.160052 \quad 0.107670 \\
& \text { H - }-16.0409634 .456856-2.285092 \\
& \text { H }-14.821398 \quad 5.719506-2.284636 \\
& \text { C }-16.558683 \quad 6.177732-1.081468 \\
& \text { H }-17.268224 \quad 5.642047 \quad-0.435021 \\
& \text { C }-17.333977 \quad 6.933138-2.167788 \\
& \text { H }-16.046580 \quad 6.901934-0.432011 \\
& \text { H }-17.851196 \quad 6.210062-2.814555 \\
& \text { H }-16.6237117 .464862-2.817026 \\
& \text { C }-18.353773 \quad 7.932624-1.607976 \\
& \text { H }-19.0645397 .400769-0.959486 \\
& \text { C }-19.128519 \quad 8.693220 \quad-2.690973 \\
& \text { H }-17.8354628 .653544-0.959650 \\
& \text { H }-19.649993 \quad 7.973252-3.337821 \\
& \text { H }-18.417565 \quad 9.223084-3.340992 \\
& \text { C }-20.143387 \quad 9.695863-2.127834 \\
& \text { H } \quad-20.8547019 .165817-1.478408 \\
& \text { C }-20.917858 \quad 10.460171-3.208394 \\
& \text { H }-19.62123110 .414309-1.479826 \\
& \text { H }-21.441907 \quad 9.742408 \quad-3.855624 \\
& \text { H }-20.206559 \quad 10.989299-3.858635
\end{aligned}
$$




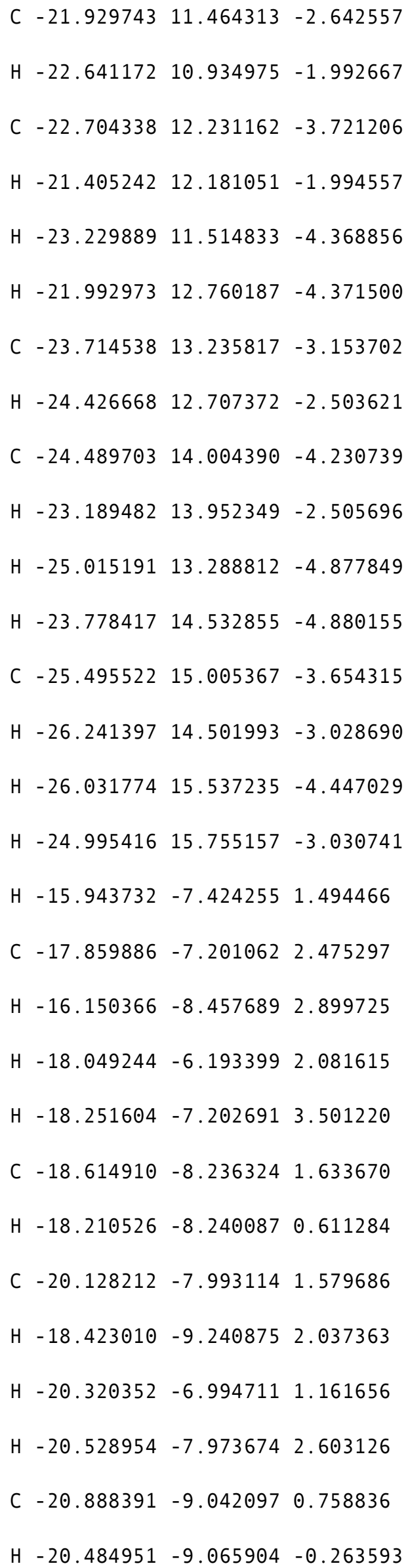




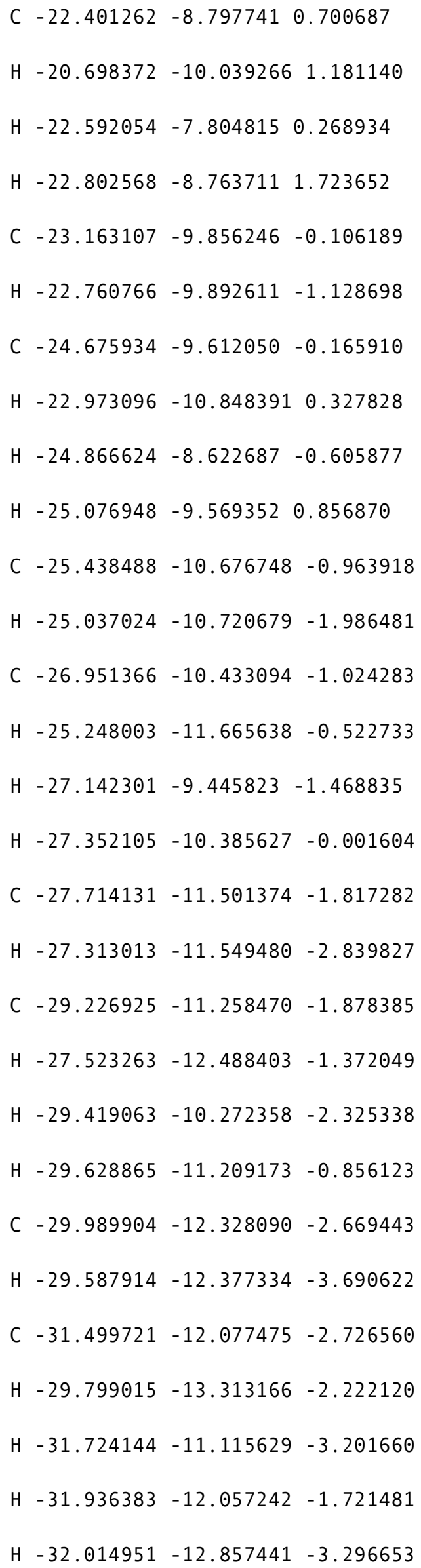


H $-5.8573498 .738606 \quad 5.404535$

C $-4.425390 \quad 9.015399 \quad 3.808777$

H $-4.190166 \quad 8.484660 \quad 5.894885$

H $-5.140353 \quad 8.820946 \quad 2.998053$

H $-3.473427 \quad 8.574808 \quad 3.484145$

C $-4.260533 \quad 10.527955 \quad 3.996615$

H $-5.207396 \quad 10.952978 \quad 4.359895$

C $-3.836817 \quad 11.261634 \quad 2.718234$

H $-3.521705 \quad 10.718200 \quad 4.788195$

H $-4.580708 \quad 11.073745 \quad 1.930923$

H $-2.892953 \quad 10.835944 \quad 2.349139$

C $-3.671941 \quad 12.774577 \quad 2.907537$

H $-4.609684 \quad 13.194388 \quad 3.299100$

C $-3.285452 \quad 13.517035 \quad 1.622515$

H $-2.911999 \quad 12.963353 \quad 3.679204$

H -4.04832213 .3296820 .853336$

H $-2.349341 \quad 13.097485 \quad 1.227131$

C $-3.121702 \quad 15.029700 \quad 1.814392$

H $-4.053979 \quad 15.445779 \quad 2.222560$

C $-2.756999 \quad 15.777546 \quad 0.526103$

H $-2.349815 \quad 15.217742 \quad 2.574350$

H $-3.53033415 .590113-0.232559$

H $-1.82542615 .362029 \quad 0.115925$

C $-2.594636 \quad 17.290108 \quad 0.719831$

H $-3.524126 \quad 17.703693 \quad 1.136730$

C $-2.241568 \quad 18.041040-0.569911$

H $-1.816636 \quad 17.477937 \quad 1.473609$

H $-3.020197 \quad 17.853403-1.323090$

H $-1.31232517 .627923-0.987747$ 
C $-2.08024519 .553570-0.375136$

$\begin{array}{llll}H & -3.008597 \quad 19.965780 & 0.045674\end{array}$

C $-1.73236720 .306163-1.665119$

H $-1.299572 \quad 19.741357 \quad 0.375934$

H $-2.513023 \quad 20.119303-2.416612$

$\begin{array}{lllll}H & -0.803829 & 19.895040 & -2.086873\end{array}$

C $-1.571238 \quad 21.818779-1.470415$

H $-2.49897922 .229740-1.049422$

C $-1.22430122 .562387-2.763620$

H $-0.79064922 .005353-0.720256$

H $\quad-2.004086 \quad 22.424668 \quad-3.521377$

H $-0.28321522 .197051-3.190363$

H $-1.115158 \quad 23.638122-2.591360$

H $3.268710-0.4001749 .492850$

C $1.601156-0.58672610 .857226$

H $2.443278 \quad 1.1156319 .818774$

H $1.407885-1.64788210 .650878$

H $\odot .616577-0.123733 \quad 11.006614$

C $2.437020-0.45535012 .135652$

H $3.420164 \quad-0.92016411 .973133$

C $1.777000-1.087302 \quad 13.367373$

H $2.635579 \quad 0.607528 \quad 12.334641$

H $1.554823-2.14318913 .157182$

H $\odot .806011-0.60472113 .547757$

C $2.635150-0.99498614 .635198$

H $3.603793-1.481367 \quad 14.450913$

C $1.979913-1.626607 \quad 15.869514$

H $2.862667 \quad 0.059975 \quad 14.844848$

H $1.734587-2.676022 \quad 15.652218$ 

H $1.020726-1.12739216 .067625$
C $2.854999-1.563084 \quad 17.127455$
H $3.812340-2.065106 \quad 16.926890$
C $2.202797-2.194442 \quad 18.363497$
H $3.104184-0.514492 \quad 17.344435$
H $1.941819-3.239142 \quad 18.141646$
H $1.251938-1.68409018 .573232$
C $3.088764-2.150167 \quad 19.614619$
H $4.038413-2.662306 \quad 19.403424$
C $2.438229-2.781443 \quad 20.851568$
H $3.352170 \quad-1.106037 \quad 19.836330$
H $2.167714 \quad-3.823125 \quad 20.626950$
H $1.492548-2.26435421 .068185$
C $3.330314-2.748905 \quad 22.098682$
H $4.275275-3.26716121 .881383$
C $2.680633-3.379784 \quad 23.336064$
H $3.602292-1.707535 \quad 22.323160$
H $2.405100 \quad-4.420277 \quad 23.111302$
H $1.737547 \quad-2.859436 \quad 23.556995$
C $3.574906-3.35319924 .581772$
H $4.516324-3.874853 \quad 24.361863$
C $2.917347-3.983857 \quad 25.812876$
H $3.850852-2.31389224 .806469$
H $2.662378 \quad-5.034296 \quad 25.631731$
H $1.990898-3.46184126 .078189$
H $3.579470 \quad-3.94847926 .684171$
H $1.784974 \quad-10.556895 \quad 2.481389$
H $1.942130 \quad-9.894405 \quad 4.101064$
C $3.818958-10.069013 \quad 3.034680$ 
H $4.178638 \quad-9.9478902 .004134$

C $4.194677-11.463282 \quad 3.549547$

H $4.337587 \quad-9.3031813 .626724$

H $3.657718-12.223693 \quad 2.964447$

H $3.845179-11.577155 \quad 4.585675$

C $5.700789-11.746093 \quad 3.486085$

H $6.045991-11.6273292 .449222$

C $6.088830-13.141302 \quad 3.990957$

H $6.237693-10.9859254 .071088$

H $5.542091-13.900807 \quad 3.413920$

H $5.757385-13.257270 \quad 5.032724$

C $7.593328-13.4253313 .902188$

H $7.921858-13.3065862 .859804$

C $7.988048-14.821014 \quad 4.400427$

H $8.140697-12.666004 \quad 4.478750$

H $7.433105-15.5798113 .830315$

H $7.670306-14.937520 \quad 5.446424$

C $9.490929-15.1067314 .292286$

H $9.806625-14.988528 \quad 3.245853$

C $9.889609-16.502915 \quad 4.785967$

H $10.046520-14.3481694 .862003$

H $9.328392-17.261013 \quad 4.221093$

H $9.581743-16.619382 \quad 5.834934$

C $11.391034-16.790537 \quad 4.663925$

H $11.697539-16.6731713 .614661$

C $11.791805-18.187114 \quad 5.154793$

H $11.952809-16.032643 \quad 5.228457$

H $11.226096-18.9446404 .593600$

H $11.490402-18.303146 \quad 6.205725$ 

C $13.291864-18.477002 \quad 5.023909$
H $13.593429-18.361642 \quad 3.972853$
C $13.693641-19.8736245 .513913$
H $13.858977-17.720128 \quad 5.584746$
H $13.125634-20.629777 \quad 4.954981$
H $13.395031-19.9876386 .564916$
C $15.192593-20.156281 \quad 5.375644$
H $15.514337-20.0843324 .330425$
H $15.446511-21.1595895 .732982$
H $15.786376-19.437980 \quad 5.952462$

\section{L-PyGNR}

606 atomic coordinates

C $-15.469118 \quad 2.993143 \quad-1.102691$

C $-15.894364 \quad 1.786899-0.546273$

N $-14.7507001 .079566-0.207937$

C $-13.617941 \quad 1.808911-0.536196$

C $-14.061498 \quad 3.006732-1.096467$

C $-14.741205-0.177425 \quad 0.376166$

C $-13.494568-0.778908 \quad 0.669882$

C $-12.253476-0.0567810 .344431$

C $-12.3265621 .235717-0.258546$

C $-10.987900-0.587556 \quad 0.599808$

C $-9.806433 \quad 0.096984 \quad 0.289444$

C $-9.8794941 .390025-0.312325$

C $-11.145074 \quad 1.920621-0.568129$

C $-8.515054-0.478123 \quad 0.563161$

N - - 7.382257 0.2491210 .230611 
C $-7.3916781 .507405-0.350706$

C $-8.6383342 .111978-0.637958$

C $-6.238598-0.460976 \quad 0.563211$

C $-6.663941-1.666658 \quad 1.120759$

C $-8.071592 \quad-1.677249 \quad 1.120739$

C $-4.956083 \quad 0.133659 \quad 0.289707$

C $-4.9026401 .428373-0.310647$

C $-6.1545282 .131359-0.636402$

C $-6.202905 \quad 3.402380-1.226737$

C $-7.410728 \quad 4.036575-1.525640$

C $-8.609094 \quad 3.382853-1.229029$

C $-3.6452111 .978616-0.565175$

C $-2.453537 \quad 1.311437-0.255996$

C $-2.506980 \quad 0.016790 \quad 0.344489$

C $-3.764409-0.533420 \quad 0.599096$

C $-1.171015 \quad 1.905427-0.530895$

N $-0.0273581 .193970-0.201235$

C $-0.017948-0.064258 \quad 0.380198$

C $-1.255097 \quad-0.686678 \quad 0.669193$

C $1.228725-0.6702210 .664456$

C $1.199496-1.940144 \quad 1.257550$

C $0.001111-2.5919331 .558348$

C $-1.206712-1.956923 \quad 1.261216$

C $2.469905 \quad 0.049349 \quad 0.333671$

C $2.3968421 .343015-0.266766$

C $1.1054531 .920280-0.535818$

C $0.661983 \quad 3.120317-1.091421$

C $-0.745673 \quad 3.111148-1.088365$

C $3.5783342 .025511-0.581521$ 
C $4.8439331 .491630-0.332807$

C $4.917016 \quad 0.197787 \quad 0.267262$

C $3.735510 \quad-0.484618 \quad 0.582218$

C $6.208434-0.379857 \quad 0.535391$

N $7.341229 \quad 0.346287 \quad 0.200327$

C $7.3317581 .604958-0.380154$

C $6.0850712 .211378-0.663320$

C $8.5688692 .227377 \quad-0.669285$

C $8.5204253 .498206-1.260034$

C $7.3125754 .133799-1.555816$

C $6.1142263 .481926-1.255087$

C $9.8207811 .523219-0.346226$

C 9.7674330 .2279590 .252938

C $8.484922-0.365739 \quad 0.528619$

C $8.059632-1.5716311 .085768$

C $6.651971-1.5803441 .089962$

C $10.959172-0.440144 \quad 0.559887$

C $12.216563 \quad 0.109795 \quad 0.304451$

C $12.2698811 .405322-0.294168$

C $11.0781472 .073265-0.601436$

C $13.468545-\odot .594398 \quad 0.627264$

C $14.705629 \quad 0.0291340 .340320$

N $14.696063 \quad 1.288416-0.238821$

C $13.5523001 .999800 \quad-0.568354$

C $15.828757 \quad 2.015645 \quad-0.571694$

C $15.385145 \quad 3.216116-1.126251$

C $13.9774883 .206326-1.124173$

C $17.1202291 .439026-0.301593$

C $17.193477 \quad 0.144576 \quad 0.297083$ 
C $15.952389-0.576819 \quad 0.624239$

C $15.923299-1.848462 \quad 1.213665$

C $14.725001-2.501715 \quad 1.511603$

C $13.517083-1.8662941 .215705$

C $18.459171-0.388027 \quad 0.548162$

C $19.640579 \quad 0.296374 \quad 0.237138$

C $19.5672751 .590701-0.361905$

C $18.3015932 .123295-0.612915$

C $20.932082-0.2793310 .508944$

N 22.064764 $0.449448 \quad 0.179034$

C $22.055025 \quad 1.708471-0.400704$

C $20.8082542 .312573-0.688366$

C $23.2920302 .333450-0.684774$

C $23.243323 \quad 3.604032-1.276042$

C $22.035365 \quad 4.237074-1.576838$

C $20.837147 \quad 3.583028-1.280369$

C $24.5440581 .632055-0.356326$

C $24.491037 \quad 0.336152 \quad 0.241334$

C $23.208558-0.260651 \quad 0.510917$

C $22.783555-1.468048 \quad 1.064979$

C $21.375878-1.479578 \quad 1.063766$

C $25.682854-0.329444 \quad 0.553119$

C $26.940222 \quad 0.223774 \quad 0.304341$

C $26.9931651 .520296-0.292262$

C $25.8013542 .185555 \quad-0.604646$

$\begin{array}{llll}\text { C } 28.192047 & -0.478286 & 0.632434\end{array}$

C $29.429003 \quad 0.149277 \quad 0.352431$

N $29.4183941 .408906-0.224433$

C $28.2756092 .118555-0.558963$ 
C $30.5514492 .139162-0.550020$

C $30.1092713 .339753-1.104870$

C $28.7017263 .327033-1.110431$

C $31.8427891 .564636-0.274174$

C $31.917079 \quad 0.2735750 .320346$

C $30.677226-0.452304 \quad 0.640794$

C $30.648287-1.725392 \quad 1.228194$

C $29.450409-2.3823601 .519176$

C $28.241384-1.750768 \quad 1.218915$

C $33.192426-0.264659 \quad 0.579821$

C $34.3514110 .431763 \quad 0.270960$

C $34.269500 \quad 1.703184-0.314527$

C $33.0300702 .258875-0.582067$

C $-17.1768391 .188998-0.279567$

C $-17.230172-0.1047150 .322899$

C $-15.978289-0.803040 \quad 0.658458$

C $-15.929851-2.0713601 .254587$

C $-14.722049 \quad-2.701648 \quad 1.561689$

C $-13.523737-2.047147 \quad 1.266583$

C - $-18.487486-0.659275 \quad 0.568458$

C $-19.679189 \quad 0.002694 \quad 0.248409$

C $-19.6258831 .296700 \quad-0.353524$

C $-18.3685431 .851226-0.599110$

C $-20.961528-0.596686 \quad 0.512106$

N $-22.105230 \quad 0.108156 \quad 0.168490$

C $-22.1148061 .365610-0.414645$

C $-20.877817 \quad 1.994318-0.690503$

C $-23.3614461 .964615-0.713410$

C $-23.332338 \quad 3.235053-1.305461$ 
C $-22.134174 \quad 3.893478-1.592322$

C $-20.926336 \quad 3.264559-1.282503$

C $-24.602358 \quad 1.237802 \quad-0.397887$

C - $-24.529228-0.053951 \quad 0.206497$

C $-23.237804-0.623218 \quad 0.492423$

C $-22.794261-1.819588 \quad 1.055788$

C $-21.386690-1.803195 \quad 1.067941$

$\begin{array}{llll}C & -25.710427 & -0.742976 & 0.507558\end{array}$

C $-26.976037 \quad-0.218018 \quad 0.240215$

C $-27.0491371 .073162-0.365681$

C $-25.8679211 .762536-0.665896$

C $-28.216599-0.945136 \quad 0.556534$

C $-29.463163-0.348658 \quad 0.251267$

N - $29.4720160 .906635-0.335003$

C $-28.340595 \quad 1.640504-0.655604$

C $-30.6161661 .608269-0.683970$

C $-30.1928102 .815328-1.239485$

C $-28.7854442 .835267-1.221966$

C $-31.8981981 .005534-0.425497$

C - $-31.952316-0.282814 \quad 0.177111$

C $-30.701487-0.976893 \quad 0.523906$

C $-30.652828-2.244433 \quad 1.122698$

C $-29.445333-2.869696 \quad 1.440799$

C $-28.246215-2.212248 \quad 1.155035$

C $-33.218961-0.849081 \quad 0.419071$

C $-34.388504-0.182201 \quad 0.085800$

C $-34.3264581 .086778-0.507391$

C $-33.096011 \quad 1.669579-0.758197$

C $29.464273-3.775615 \quad 2.111886$ 
C $29.529159-4.8880601 .046509$

C $29.545683-6.298652 \quad 1.646644$

C $29.622426-7.4098810 .592356$

C $29.639278 \quad-8.821922 \quad 1.190644$

C $29.726277 \quad-9.933682 \quad 0.137836$

C $29.743404-11.3455610 .736368$

C $29.838310-12.457684-0.315365$

C $29.855746-13.8693290 .283700$

C $29.956262-14.981721-0.767210$

C $29.973945-16.393174-0.167709$

C $30.077805-17.505899-1.217685$

C $30.095624-18.917425-0.618280$

C $30.200720-20.022456-1.673549$

C $22.0227095 .627495 \quad-2.175991$

C $21.958537 \quad 6.745084-1.115954$

C $21.9428888 .152597-1.723282$

C $21.8666269 .269258-0.674732$

C $21.85048910 .678096-1.280533$

C $21.76376211 .795487-0.233696$

C $21.747228 \quad 13.204097 \quad-0.839888$

C $21.65243314 .321939 \quad 0.205764$

C $21.635518 \quad 15.730290 \quad-0.401014$

C $21.53500916 .848424 \quad 0.643780$

C $21.517807 \quad 18.256580 \quad 0.036568$

C $21.413906 \quad 19.375038 \quad 1.080429$

C $21.396552 \quad 20.783275 \quad 0.473330$

C $21.29142921 .894064 \quad 1.522536$

C $14.737460-3.893882 \quad 2.106704$

C $14.797939-5.008294 \quad 1.043093$ 
C $14.813462-6.417768 \quad 1.645865$

C $14.886101 \quad-7.531038 \quad 0.593444$

C $14.902091 \quad-8.941952 \quad 1.194404$

C $14.985300-10.0558090 .143511$

C $15.001647-11.4665610 .744712$

C $15.093061-12.580800-0.305088$

C $15.109750-13.9913220 .296635$

C $15.207010-15.105828-0.752339$

C $15.223954-16.516164-0.150196$

C $15.324709-17.630995-1.198240$

C $15.341786-19.041409-0.596204$

C $15.443830-20.148552-1.649558$

C $7.3002885 .524679-2.153909$

C $7.241030 \quad 6.641459-1.092722$

C $7.225743 \quad 8.049573-1.698664$

C $7.1540799 .165265-0.648750$

C $7.138404 \quad 10.574794-1.252956$

C $7.05597011 .691106-0.204616$

C $7.03998313 .100463-0.809088$

C $6.94919714 .217162 \quad 0.238145$

C $6.932897 \quad 15.626289-0.366847$

C $6.836167 \quad 16.743249 \quad 0.679561$

C $6.81962618 .152195 \quad 0.074163$

C $6.719349 \quad 19.269467 \quad 1.119648$

C $6.70268320 .678497 \quad 0.514369$

C $6.60111121 .788091 \quad 1.565186$

C $0.013411-3.982137 \quad 2.158017$

C $0.074597-5.1001021 .098191$

C $0.090079-6.507502 \quad 1.705790$ 
C $0.163755-7.624379 \quad 0.657277$

C $0.179749-9.033182 \quad 1.263168$

C $0.264211-10.150677 \quad 0.216249$

C $0.280602-11.559303 \quad 0.822413$

C $0.373384-12.677175-0.223392$

C $\odot .390146-14.0855720 .383286$

C $0.488819-15.203693-0.661700$

C $0.505854-16.611911-0.054626$

C $0.608026-17.730335-1.098696$

C $0.625202-19.138640-0.491746$

C $0.728636-20.249387-1.541163$

C $-7.423071 \quad 5.427976-2.122524$

C $-7.485887 \quad 6.543673-1.060396$

C $-7.5012097 .952395-1.664926$

C $-7.576070 \quad 9.066896-0.613966$

C $-7.59181910 .477082-1.216636$

C $-7.67713211 .592133-0.167180$

C $-7.69321613 .002177-0.770045$

C $-7.78662014 .117578 \quad 0.278343$

C $-7.803036 \quad 15.527408-0.325008$

C $-7.902191 \quad 16.643054 \quad 0.722575$

C $-7.91886318 .052707 \quad 0.118828$

C $-8.021446 \quad 19.1686651 .165495$

C $-8.03825620 .578402 \quad 0.561868$

C $-8.14209321 .686673 \quad 1.613859$

C $-14.709426-4.0897832 .166126$

C $-14.639086 \quad-5.211210 \quad 1.110545$

C $-14.623175-6.616438 \quad 1.723136$

C $-14.540924 \quad-7.736784 \quad 0.678979$ 

C $-14.524302-9.143394 \quad 1.289925$
C $-14.431869-10.264349 \quad 0.247395$
C $-14.414700 \quad-11.670783 \quad 0.858604$
C $-14.314530-12.792084-0.182836$
C $-14.296877 \quad-14.198304 \quad 0.428847$
C $-14.191295-15.319815-0.611819$
C $-14.173292-16.725873 \quad 0.000214$
C $-14.064539-17.847656-1.039576$
C $-14.046356-19.253815-0.427701$
C $-13.936498-20.367924-1.472893$
C $-29.433265 \quad-4.256794 \quad 2.047800$
C $-29.351973 \quad-5.379996 \quad 0.994944$
C $-29.336309 \quad-6.784054 \quad 1.610226$
C $-29.244492 \quad-7.906209 \quad 0.568821$
C $-29.227705 \quad-9.311598 \quad 1.182565$
C $-29.126898-10.434366 \quad 0.142771$
C $-29.109279-11.839557 \quad 0.756818$
C $-29.001693-12.962660-0.281933$
C $-28.983406-14.367636 \quad 0.332579$
C $-28.871107-15.490931-0.705454$
C $-28.852358-16.895755-0.090617$
C $-28.737324-18.019306-1.127819$
C $-28.718332-19.424240 \quad-0.513161$
C $-28.602374-20.540118-1.555802$
$\begin{array}{lllll}H & -35.239487 & 1.612600 & -0.770117\end{array}$
$\begin{array}{lllll}H & -35.349814 & -0.645599 & 0.285344\end{array}$
C $-22.147119 \quad 5.284375-2.190380$
C $-22.221746 \quad 6.400609-1.129581$
C $-22.2378107 .808857-1.735201$ 

C - $22.323622 \quad 8.923777-0.685524$
C $-22.340345 \quad 10.333526-1.289192$
C $-22.43578211 .448916-0.240968$
C $-22.453005 \quad 12.858550-0.844762$
C $-22.555788 \quad 13.974238 \quad 0.202443$
C $-22.57346315 .383676-0.401787$
C $-22.681410 \quad 16.499580 \quad 0.644653$
C $-22.699422 \quad 17.908851 \quad 0.040055$
C $-22.810410 \quad 19.025052 \quad 1.085604$
C $-22.828607 \quad 20.434413 \quad 0.481140$
C $-22.94068321 .542924 \quad 1.532035$
H $25.608059-1.3110591 .005214$
H 25.876428 $3.167581-1.055798$
H $18.549426-1.3678221 .001373$
H $18.2113613 .103461-1.065318$
H $10.883986-1.4211181 .013292$
H $11.1533543 .054446-1.054377$
H $31.579477 \quad-2.2250391 .472449$
H $27.318626-2.2695841 .455060$
H $30.742540 \quad 4.137246-1.465517$
H $28.0580414 .113772-1.476479$
H $23.427702-2.254777 \quad 1.430116$
H $20.744133-2.276826 \quad 1.427787$
H $24.166645 \quad 4.119903-1.516317$
H $19.9059124 .082715-1.524519$
H $16.854523-2.3499811 .454060$
H $12.593725 \quad-2.381626 \quad 1.457024$
H $16.0170294 .012361-1.492195$
H $13.333513 \quad 3.993717-1.488199$ 

H $3.825596-1.4642221 .035871$
H $3.488248 \quad 3.005004-1.035405$
H $9.4438194 .012409-1.503594$
H $5.1830413 .983580-1.495351$
H $8.703559-2.359259 \quad 1.449357$
H $6.020044 \quad-2.375910 \quad 1.457315$
H $33.281224-1.2461631 .031573$
H $35.319863 \quad-0.0104490 .483594$
H $35.1741912 .252083-0.558197$
H $32.963163 \quad 3.242863-1.035235$
H $-3.569925 \quad 2.959010-1.019811$
H $-3.839696-1.514131 \quad 1.053047$
H $1.2939513 .915855-1.458761$
H $-1.3895563 .898381-1.452889$
H $2.130656-2.441301 \quad 1.498951$
H $-2.130132-2.471088 \quad 1.504761$
H $-5.279480 \quad 3.918018-1.467134$
H $-9.5402313 .883453-1.471663$
H $-6.020061 \quad-2.452947 \quad 1.487323$
H $-8.703566 \quad-2.473171 \quad 1.487234$
H $-33.044474 \quad 2.651719-1.217343$
$\begin{array}{lllll}\text { H } & -33.292420 & -1.829297 & 0.876327\end{array}$
H $-30.838326 \quad 3.595621-1.615703$
H $-28.154185 \quad 3.634370-1.582842$
H $-31.576051 \quad-2.7639841 .355170$
H $-27.315733 \quad-2.706388 \quad 1.412994$
H $-25.958201 \quad 2.739794-1.124566$
H $-25.620399 \quad-1.720877 \quad 0.964891$
H $-24.263419 \quad 3.731596-1.556488$ 


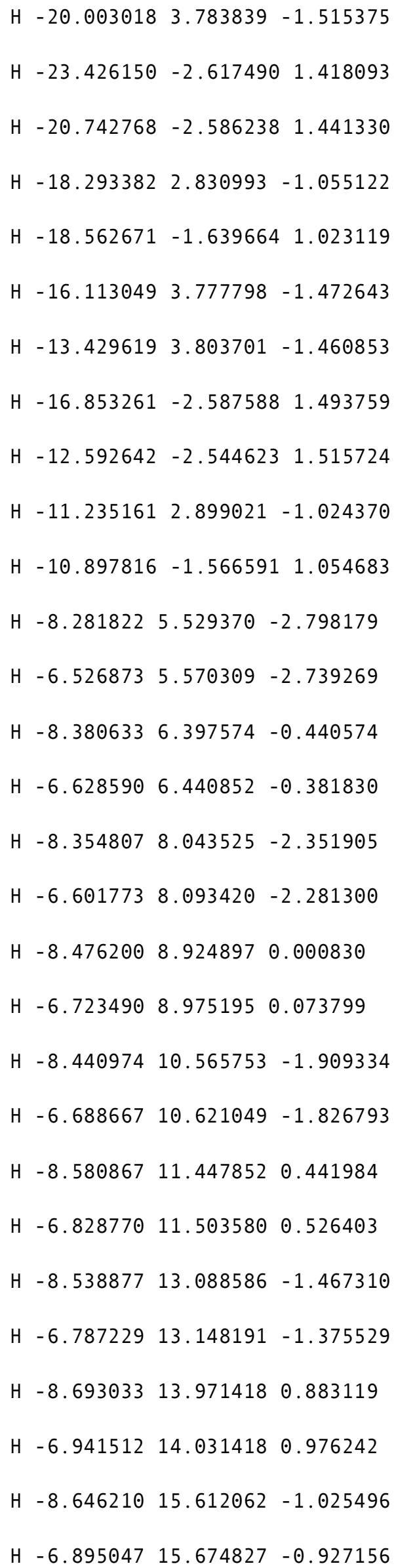


H $-8.81044916 .495553 \quad 1.324262$

H $-7.059374 \quad 16.558612 \quad 1.423465$

H $\quad-8.760538 \quad 18.136206-0.583638$

$\begin{array}{llll}\text { H } & -7.009637 & 18.200923 & -0.481306\end{array}$

H $\quad-8.930885 \quad 19.021524 \quad 1.765747$

H $-7.180008 \quad 19.086369 \quad 1.868522$

H $-8.87888720 .660588-0.140591$

$\begin{array}{lllll}H & -7.129043 & 20.725951 & -0.036808\end{array}$

H $-9.059200 \quad 21.586703 \quad 2.205578$

H $-8.151801 \quad 22.679232 \quad 1.151757$

H $-7.296413 \quad 21.652673 \quad 2.310198$

H $-0.882183-4.122756 \quad 2.776023$

H $0.872839-4.0825492 .832968$

H $-0.783414-4.998416 \quad 0.420360$

H $\odot .968712-4.955693 \quad 0.477062$

H $-0.808844-6.6469262 .323275$

H $0.944258-6.597324 \quad 2.392222$

H $-0.689407-7.534061-0.029947$

H $1.063378 \quad-7.483972 \quad 0.041373$

H $-0.722987 \quad-9.1756311 .874295$

H $1.029381-9.120354 \quad 1.955474$

H $-0.584625-10.063670-0.476946$

H $1.167535-10.007902-0.393879$

H $-0.625035-11.703867 \quad 1.428766$

H $1.126666-11.644092 \quad 1.519391$

H $-0.472123-12.592660-0.921007$

H $1.279451-12.532451-0.829033$

H $-0.517535 \quad-14.231594 \quad 0.986238$

H $1.233675-14.1685411 .083549$ 


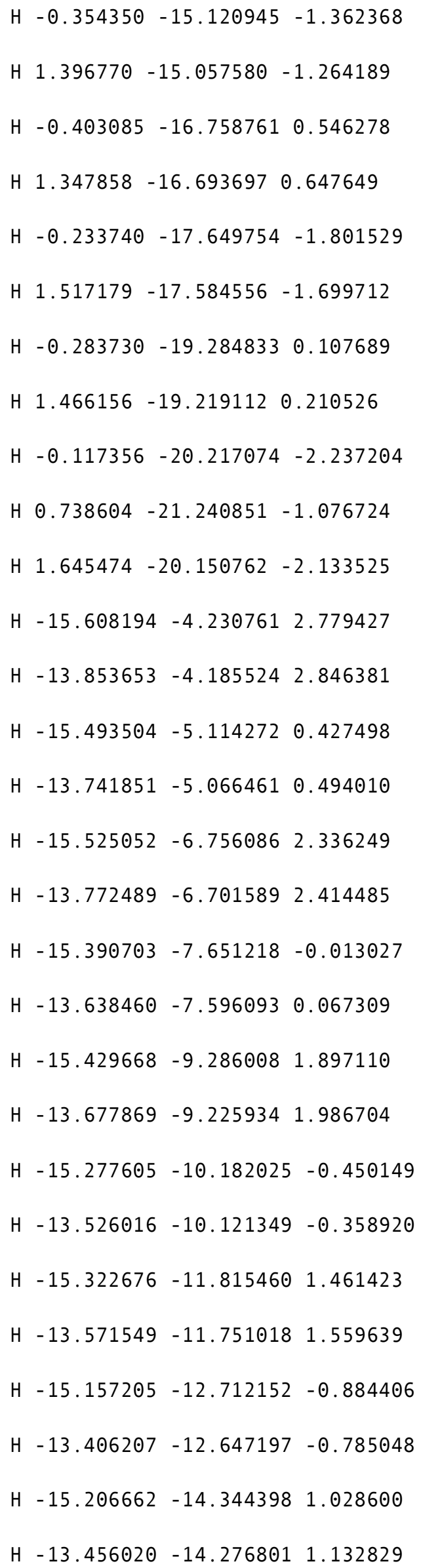




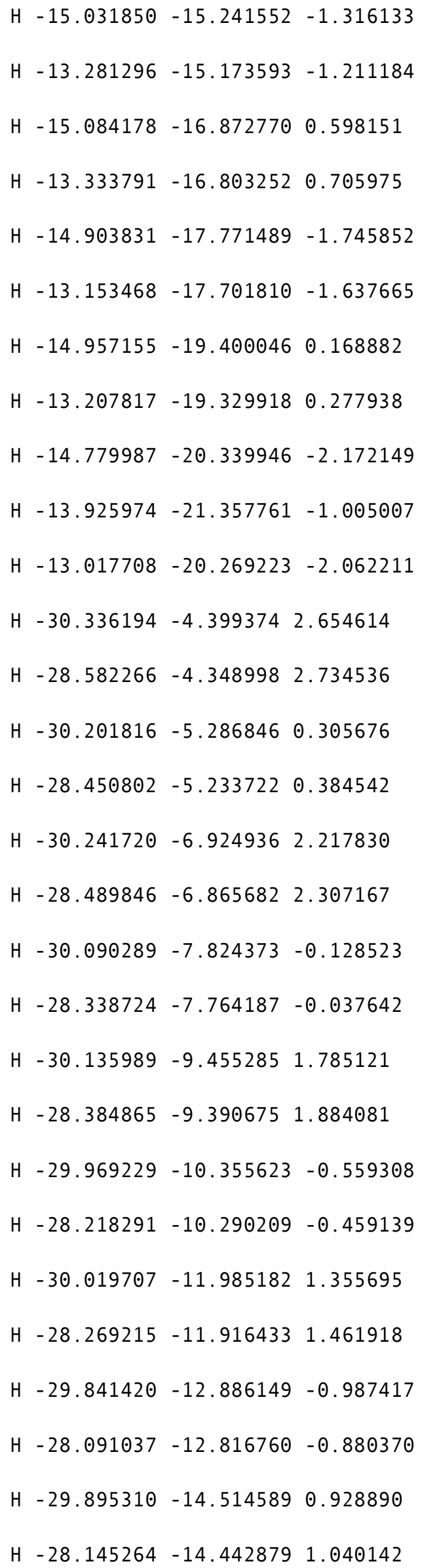




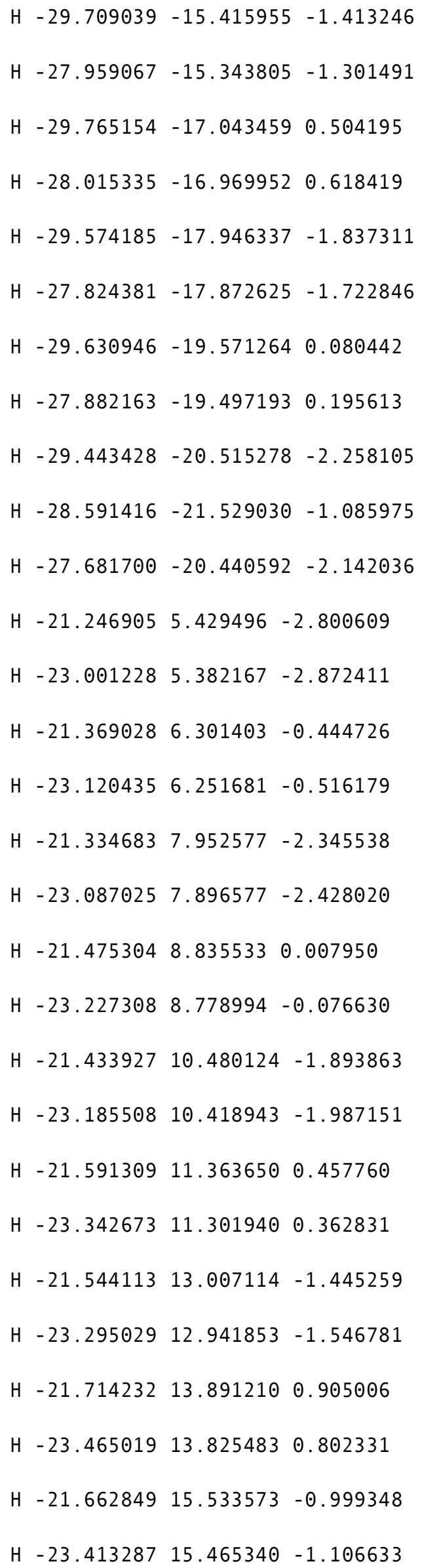




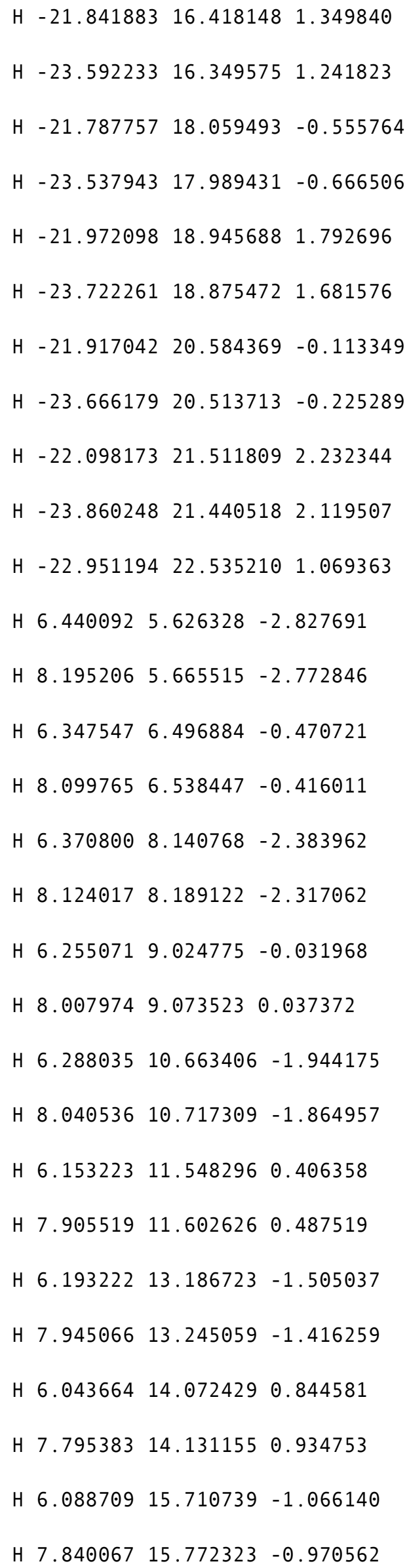



H 5.92871116 .5971391 .282798
H $7.67998116 .659011 \quad 1.379273$
H $5.97699518 .235460 \quad-0.627184$
H $7.728087 \quad 18.299047 \quad-0.527461$
H $5.810668 \quad 19.123692 \quad 1.721380$
H $7.561737 \quad 19.187402 \quad 1.821563$
H $5.86112020 .760443 \quad-0.187002$
H $7.61115420 .824692-0.085762$
H $5.684766 \quad 21.689477 \quad 2.158312$
H $6.59146122 .780106 \quad 1.101919$
H $7.447745 \quad 21.754315 \quad 2.260375$
H $13.842162 \quad-4.036466 \quad 2.724699$
H $15.597229-3.9966352 .780860$
H $13.939608 \quad-4.904160 \quad 0.366037$
H $15.691768-4.8619220 .422015$
H $13.914918-6.559078 \quad 2.263476$
H $15.668086-6.510185 \quad 2.331396$
H $14.032489-7.438083-0.092870$
H $15.785337-7.388753-0.022593$
H $13.999796 \quad-9.086220 \quad 1.805757$
H $15.752251-9.031844 \quad 1.885712$
H $14.135935-9.966056-0.548687$
H $15.888183-9.911231-0.466845$
H $14.096476-11.6128891 .351340$
H $15.848279-11.5541391 .440653$
H $14.246988-12.493485-1.001671$
H $15.998666-12.434332-0.911000$
H $14.202539-14.139063 \quad 0.899876$
H $15.953861-14.077107 \quad 0.995857$ 

H $14.363262-15.020265-1.451971$
H $16.114497-14.958013-1.355113$
H $14.315478-16.664705 \quad 0.450993$
H $16.066538-16.6007690 .551047$
H $14.482364-17.547597-1.900050$
H $16.233401-17.483534-1.799544$
H $14.433306-19.1892870 .003502$
H $16.183309-19.124687$ ๑. 105059
H $14.597246 \quad-20.113472 \quad-2.344744$
H $15.453782-21.141626-1.188570$
H $16.360194-20.048261-2.242375$
H $21.164395 \quad 5.727264 \quad-2.852454$
H $22.9192725 .769244-2.792332$
H $21.063424 \quad 6.599681-0.496487$
H $22.815423 \quad 6.644030-0.436613$
H $21.0897608 .241851-2.411100$
H $22.842707 \quad 8.292855-2.339260$
H $20.9661369 .128064-0.060267$
H $22.7187829 .179549 \quad 0.013812$
H $21.001788 \quad 10.764709-1.974056$
H $22.754000 \quad 10.821214 \quad-1.890345$
H 20.85969311 .6520650 .375186
H $22.611711 \quad 11.709074 \quad 0.460653$
H $20.901991 \quad 13.288336-1.537940$
H $22.653539 \quad 13.349223-1.445089$
H $20.745718 \quad 14.176663 \quad 0.810310$
H $22.497151 \quad 14.238000 \quad 0.904399$
H $20.79273515 .812716-1.102244$
H $22.543797 \quad 15.876807-1.002935$ 

H $20.626478 \quad 16.701816 \quad 1.245281$
H $22.377459 \quad 16.766237 \quad 1.345374$
H $20.676496 \quad 18.337827-0.666603$
H $22.42729618 .403891-0.563383$
H $20.504214 \quad 19.228793 \quad 1.680523$
H $22.254995 \quad 19.295006 \quad 1.784132$
H $20.55626720 .863209-0.229806$
H $22.30601020 .929923-0.125188$
H 20.37404921 .7949752 .113986
H 21.28137322 .8854811 .057996
H $22.13673921 .862289 \quad 2.219428$
H $28.567876 \quad-3.9211642 .727647$
H $30.322816-3.878048 \quad 2.787660$
H $28.672257 \quad-4.7841690 .367604$
H $30.424228 \quad-4.738955 \quad 0.427867$
H $28.646002 \quad-6.442607 \quad 2.261993$
$\begin{array}{llll}\text { H } & 30.398934 & -6.390978 & 2.333897\end{array}$
H $28.770214-7.316973-0.095712$
H $30.522827-7.265049-0.021410$
H $28.735926-8.968676 \quad 1.799838$
H $30.488121 \quad-8.9118811 .883557$
H $28.878218-9.843834-0.555956$
H $30.630223-9.786667-0.470379$
H $28.837270-11.4942611 .340976$
H $30.588815-11.4333211 .433763$
H $28.993438-12.370177-1.013386$
H $30.744871-12.308866-0.919281$
H 28.947660 -14.0193650 .885053$
H $30.698728-13.9553680 .984246$ 

H $29.113625-14.895903-1.468154$
H $30.864617-14.831621-1.368112$
H $29.064654-16.543963 \quad 0.431685$
H $30.815466-16.478067 \quad 0.534770$
H $29.236515-17.422214-1.920730$
H $30.987310-17.356194-1.817203$
H $29.186354-19.067535-0.020328$
H $30.936111-19.001002 \quad 0.084184$
H $29.355214-19.987102-2.370036$
H $30.211144-21.016383-1.214413$
H $31.117919-19.919935-2.264691$ 


\section{REFERENCES}

[1] M. Daigle, A. Picard - Lafond, E. Soligo, J. F. Morin, Angew. Chem. Int. Ed. 2016, 128, 2082-2087.

[2] B. C. Thompson, Y.-G. Kim, J. R. Reynolds, Macromolecules 2005, 38, 53595362.

[3] Daigle, M.; Miao, D.; Lucotti, A.; Tommasini, M.; Morin, J.-F. Angew. Chem. Int. Ed. 2017, 56, 6213-6217

[4] Gaussian 09, Revision D.01, M. J. Frisch, G. W. Trucks, H. B. Schlegel, G. E. Scuseria, M. A. Robb, J. R. Cheeseman, G. Scalmani, V. Barone, B. Mennucci, G. A. Petersson, H. Nakatsuji, M. Caricato, X. Li, H. P. Hratchian, A. F. Izmaylov, J. Bloino, G. Zheng, J. L. Sonnenberg, M. Hada, M. Ehara, K. Toyota, R. Fukuda, J. Hasegawa, M. Ishida, T. Nakajima, Y. Honda, O. Kitao, H. Nakai, T. Vreven, J. A. Montgomery, Jr., J. E. Peralta, F. Ogliaro, M. Bearpark, J. J. Heyd, E. Brothers, K. N. Kudin, V. N. Staroverov, T. Keith, R. Kobayashi, J. Normand, K. Raghavachari, A. Rendell, J. C. Burant, S. S. Iyengar, J. Tomasi, M. Cossi, N. Rega, J. M. Millam, M. Klene, J. E. Knox, J. B. Cross, V. Bakken, C. Adamo, J. Jaramillo, R. Gomperts, R. E. Stratmann, O. Yazyev, A. J. Austin, R. Cammi, C. Pomelli, J. W. Ochterski, R. L. Martin, K. Morokuma, V. G. Zakrzewski, G. A. Voth, P. Salvador, J. J. Dannenberg, S. Dapprich, A. D. Daniels, O. Farkas, J. B. Foresman, J. V. Ortiz, J. Cioslowski, and D. J. Fox, Gaussian, Inc., Wallingford CT, 2013.

[5] Molecular Vibrations: The Theory of Infrared and Raman Vibrational Spectra, E. B. Wilson Jr., J. C. Decius, P. C. Cross, McGraw Hill, 1955. 